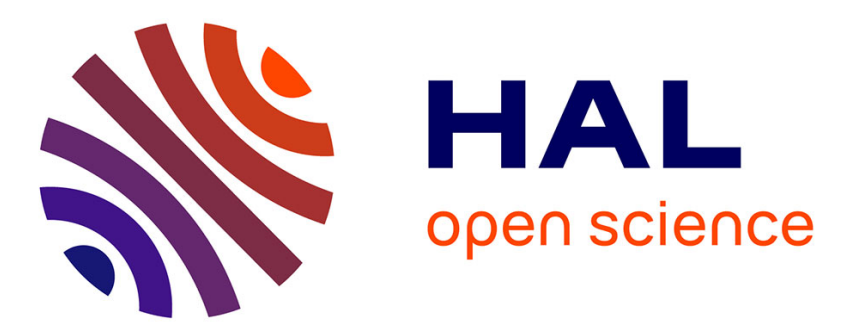

\title{
Single-molecule magnet behavior in heterolopetic Dy 3+ -chloro-diazabutadiene complexes: influence of the nuclearity and ligand redox state
}

Jérome Long, Aleksei Tolpygin, Anton Cherkasov, Konstantin A. Lyssenko, Yannick Guari, Joulia Larionova, Alexander Trifonov

\section{To cite this version:}

Jérome Long, Aleksei Tolpygin, Anton Cherkasov, Konstantin A. Lyssenko, Yannick Guari, et al.. Single-molecule magnet behavior in heterolopetic Dy 3+ -chloro-diazabutadiene complexes: influence of the nuclearity and ligand redox state. Dalton Transactions, 2020, 49 (34), pp.11890-11901. 10.1039/D0DT02305A . hal-02927056

\section{HAL Id: hal-02927056 https://hal.science/hal-02927056}

Submitted on 27 Nov 2020

HAL is a multi-disciplinary open access archive for the deposit and dissemination of scientific research documents, whether they are published or not. The documents may come from teaching and research institutions in France or abroad, or from public or private research centers.
L'archive ouverte pluridisciplinaire HAL, est destinée au dépôt et à la diffusion de documents scientifiques de niveau recherche, publiés ou non, émanant des établissements d'enseignement et de recherche français ou étrangers, des laboratoires publics ou privés. 


\title{
Single-molecule magnet behavior in heterolopetic $\mathrm{Dy}^{3+}$-chloro- diazabutadiene complexes: influence of the nuclearity and ligand redox state.
}

\author{
Jérôme Long*, ${ }^{\text {a }}$ Aleksei O. Tolpygin, ${ }^{b}$ Anton V. Cherkasov, ${ }^{b}$ Konstantin A. Lyssenko, ${ }^{\text {cd }}$ Yannick \\ Guari $^{\mathrm{a}}$, Joulia Larionova ${ }^{\mathrm{a}}$ and Alexander A. Trifonov*b,c

\begin{abstract}
We report the synthesis, structure and magnetic properties' investigations of a series of new dysprosium heteroleptic mono- and dinuclear complexes based on the association of chloride and different diazabutadiene $\left(D^{2} D^{2 R}=[2,6\right.$ $\left.{ }_{i} \mathrm{Pr}_{2} \mathrm{C}_{6} \mathrm{H}_{3} \mathrm{~N}-\mathrm{CR}=\mathrm{CR}-\mathrm{NC}_{6} \mathrm{H}_{3} i \mathrm{Pr}_{2}-2,6\right] ; \mathrm{R}=\mathrm{H}$, Me) ligands showing different redox states. While using dianionic $D A D^{2 \mathrm{R}}$ ligands affords the formation of dichloro-bridged dinuclear complexes $\left[\mathrm{Dy}_{2}\left(\mathrm{DAD}^{2 R}\right)(\mu-\mathrm{Cl})_{2}(\mathrm{THF})_{2}\right](\mathrm{R}=\mathrm{H}(\mathbf{1}), \mathrm{Me}(\mathbf{2}))$, two different mononuclear complexes of general formula $\left[\mathrm{DyCl}_{2}\left(\mathrm{DAD}^{2 \mathrm{R}}\right)(\mathrm{THF})_{2}\right](\mathrm{R}=\mathrm{H}(\mathbf{3}), \mathrm{Me}(\mathbf{4}))$ could be obtained with either a radical monoanionic and a monoanionic $D A D^{2 R}$ state, respectively. Remarkably, all the complexes exhibit a slow relaxation of their magnetization where the relaxation dynamics depends on both, the nuclearity of the system and the $D A D^{2 R}$ redox state.
\end{abstract}

\section{Introduction}

Owing to their exceptional physical properties, such as luminescence and magnetism, lanthanide ions continue to draw attention in countless fields. For instance, SingleMolecule Magnets (SMMs) designed with lanthanide ions ${ }^{1-4}$ are frequently considered as candidates for future applications including quantum computing, data storage or spintronics. ${ }^{1,5-7}$ These coordination complexes show a slow relaxation of their magnetization resulting in a magnetic bistability at the molecular scale. This remarkable effect occurs from the emergence of an anisotropic barrier that prevents the reversal of the magnetization of opposites $\pm m$, states related to the $4 f$ ion. The height of this barrier, which is in some extent related to the working temperature of the $\mathrm{SMM}^{8-9}$ could be enhanced by carefully controlling the coordination environment of the lanthanide ion. ${ }^{10-11}$ As example and for mononuclear complexes, the oblate electronic density of $\mathrm{Dy}^{3+}$ ions could be efficiently stabilized by the accurate choice of the nature and the position of surrounding ligands to create a high axial crystal-field that will magnify the magnetic anisotropy. On the other hand, it is of crucial importance to reduce the Quantum Tunnelling of the Magnetization (QTM), which creates underbarrier relaxations. These requisites are therefore responsible for the blocking of the magnetization although intricate spin-lattice relaxation mechanisms, such as Raman or direct process could also reduce the magnetic performances through other relaxation pathways. ${ }^{8,}$ 12-15 Following these principles, numerous mononuclear SMMs with large anisotropic barriers exceeding $1000 \mathrm{~cm}^{-1}$ and presenting blocking temperatures that could surpass liquid nitrogen boiling point have been reported within the last few years. ${ }^{11-12,}$ 16-22 Among those, the family of SMM with organometallic ligands, such as cyclopentadienyl derivatives, holds the first place in terms of the SMM performances, ${ }^{9,}{ }^{23}$ while various
Werner type complexes have also been investigated and certain of them present a relatively high energy barriers. ${ }^{16,20-21 \text {, }}$ 24-29

Besides, an important impact on magnetic relaxation may also be provided by the presence of magnetic interactions. Yet, the rationalization of this parameter remains for the moment unclear. $^{30}$ These magnetic interactions in the vicinity of a lanthanide ion could be generated following two routes: i) assembling lanthanide ions into polynuclear structures using bridging diamagnetic ligands, and/or ii) using radical ligands which may be particularly appropriate to promote strong interactions and overcome the problem of the intern character of the $4 f$ orbitals that engenders weak exchange interactions. ${ }^{31}$ In the first case, dinuclear complexes represent obviously the simplest model to study the influence of exchange interactions over the slow relaxation dynamics. ${ }^{32}$ Different literature examples have shown a decline of the anisotropy barrier in polynuclear $\mathrm{Dy}^{3+}$ based complexes due to the mixing of the states and/or the QTM increase. ${ }^{33}$ On the other hand, several cases show their positive impact caused by an exchange bias effect that shifts the usual zero-field QTM relaxation, ${ }^{34-39}$ which could eventually lead to a large magnetic coercivity. ${ }^{40}$ For the second strategy, numerous lanthanide-based systems containing miscellaneous radical ligands, such as nitronyl nitroxides, ${ }^{41-42}$ semiquinoates, ${ }^{43}$ verdazyls, ${ }^{44}$ triazinyl, ${ }^{45}$ bipyrimidyl, ${ }^{46}$ pyridyl-pyrazine, ${ }^{47}$ oxidized phtalocyanine, ${ }^{48}$ indigo, ${ }^{49}$ iminopyridine, ${ }^{50}$ or dinitrogen have been reported. ${ }^{40}$ Remarkably, the latest example has hold the record for the highest coercitivity and blocking temperature for many years. ${ }^{40}$ Nevertheless, the relaxation dynamic in lanthanidebased SMMs being extremely sensitive to the coordination environment of the lanthanide site, it appears difficult to draw a general picture and identifying the critical parameters.

In this sense, we have been investigating for several years the use of diazabutadiene ligands $\left(D^{2} D^{2 R}=\left[2,6-i \mathrm{Pr}_{2} \mathrm{C}_{6} \mathrm{H}_{3} \mathrm{~N}-\right.\right.$ $\left.\mathrm{CR}=\mathrm{CR}-\mathrm{NC}_{6} \mathrm{H}_{3} i \mathrm{Pr}_{2}-2,6\right]$ ) for designing homo or heteroleptic 
lanthanide based SMMs. ${ }^{51-54}$ Such ligands are interesting candidates for the synthesis of new SMMs because: $(i)$ they could act both, as $\sigma$ ( $\mathrm{N}$ atoms) and $\pi$ ( $\mathrm{C}=\mathrm{C}$ bond) electron donors, (ii) they usually present a dianionic character when coordinated to $\mathrm{Ln}^{3+}$ ions, (iii) their great steric tunability through modification of the substituent groups may be viewed as an important advantage to finely tune the coordination environment, (iv) the Dy- $\mathrm{N}$ distances were found relatively short, that gives rise to a relatively large crystal-field splitting and the appearance of a genuine SMM behaviour. ${ }^{52}$ Another interesting feature of diazabutadiene system consists also in the presence of several redox states including a radical-anionic one, which may be attractive to provide strong exchange interactions with lanthanides while keeping the chelating $\mathrm{N}, \mathrm{N}-$ ligand scaffold. ${ }^{55-56}$ In this line of thought, some of us reported a few years ago, paramagnetic mononuclear dichloro yttrium and lutetium complexes based on both monoanionic [(2,6$\left.\mathrm{iPr}_{2} \mathrm{C}_{6} \mathrm{H}_{3}\right) \mathrm{N}=\mathrm{C}(\mathrm{Me}) \mathrm{C}\left(=\mathrm{CH}_{2}\right) \mathrm{N}\left(\mathrm{C}_{6} \mathrm{H}_{3}-\mathrm{iPr}_{2}-2,6\right]^{-}$and monoanionicradical $\left[2,6-\mathrm{iPr}_{2} \mathrm{C}_{6} \mathrm{H}_{3} \mathrm{NCHCHNC}_{6} \mathrm{H}_{3} \mathrm{IPr}_{2}-2,6\right]^{-\cdot}$ ligand. ${ }^{55,}{ }_{57}$ However, this redox-active aspect of the diazabutadiene system has never been implemented in coordination with highly anisotropic lanthanide ions, such as $\mathrm{Dy}^{3+}$ to design original SMMs.

In this article, we report the syntheses, structures and magnetic properties of four di- and mononuclear dysprosium complexes, based on $D^{2} D^{2 R}\left(D A D^{2 R}=\left[2,6-i \mathrm{Pr}_{2} \mathrm{C}_{6} \mathrm{H}_{3} \mathrm{~N}-\mathrm{CR}=\mathrm{CR}-\right.\right.$ $\left.\mathrm{NC}_{6} \mathrm{H}_{3} i \mathrm{Pr}_{2}-2,6\right] ; \mathrm{R}=\mathrm{H}, \mathrm{Me}$ ) available in two different redox states and associated with bridging or terminal chloro ligands. While using dianionic $D A D^{2 R}$ ligands affords the formation of chloro-bridged dinuclear complexes, we show that the use of radical-monoanionic $D A D^{2 R}$ ligands leads to mononuclear complexes with different $D A D^{2 R}$ redox state depending on the nature of the substituent. Remarkably, all the complexes exhibit a slow relaxation of the magnetization arising from a SMM behavior, but with distinct relaxation dynamics. The similar coordination environment of all the complexes in this series allows directly comparing the influence of the magnetic interactions and the different $D A D^{2 R}$ state over the relaxation dynamics.

\section{Results and Discussions}

\section{Synthesis}

The synthesis featuring four $\mathrm{Dy}^{3+}$ diazabutadiene chloro complexes was carried out in order to probe the influence of the following factors over the relaxation dynamics: $i$ ) the intramolecular $\mathrm{Dy}^{3+}-\mathrm{Dy}^{3+}$ interactions through chloro ligand in dinuclear complexes; ii) the impact of DAD's substituent groups; iii) the influence of radical-Dy ${ }^{3+}$ interactions.

The salt metathesis approach was employed for the synthesis of dinuclear chloro complex with $\mathrm{Dy}^{3+}$ coordinated by enediamido ligands with different backbones. Dipotassium derivatives $\mathrm{K}_{2}\left[2,6-\mathrm{iPr}{ }_{2} \mathrm{C}_{6} \mathrm{H}_{3} \mathrm{NC}(\mathrm{R}) \mathrm{C}(\mathrm{R}) \mathrm{NC}_{6} \mathrm{H}_{3} \mathrm{iPr} \mathrm{Pr}_{2}-2,6\right](\mathrm{THF})_{\mathrm{n}} \quad(\mathrm{R}=$ $\mathrm{H}$, Me) were in situ obtained by the reduction of diazabutadiene with 2 equivalents of metallic $\mathrm{K}$ in THF. The subsequent reactions with anhydrous $\mathrm{DyCl}_{3}$ (molar ratio 1:1; THF, $20^{\circ} \mathrm{C}$ ) afforded the target $\left[\mathrm{Dy}(\mathrm{DAD})^{2 \mathrm{R}}\left(\mu^{2}-\mathrm{Cl}\right)(\mathrm{THF})_{2}\right]_{2}(\mathrm{R}=\mathrm{H}$ (1), Me (2)) complexes (Scheme 1). Complexes 1 and 2 were isolated as red (1) and orange (2) crystals in 67 and $61 \%$ yield, respectively, after recrystallization of the reaction products from a THF/hexane mixture.
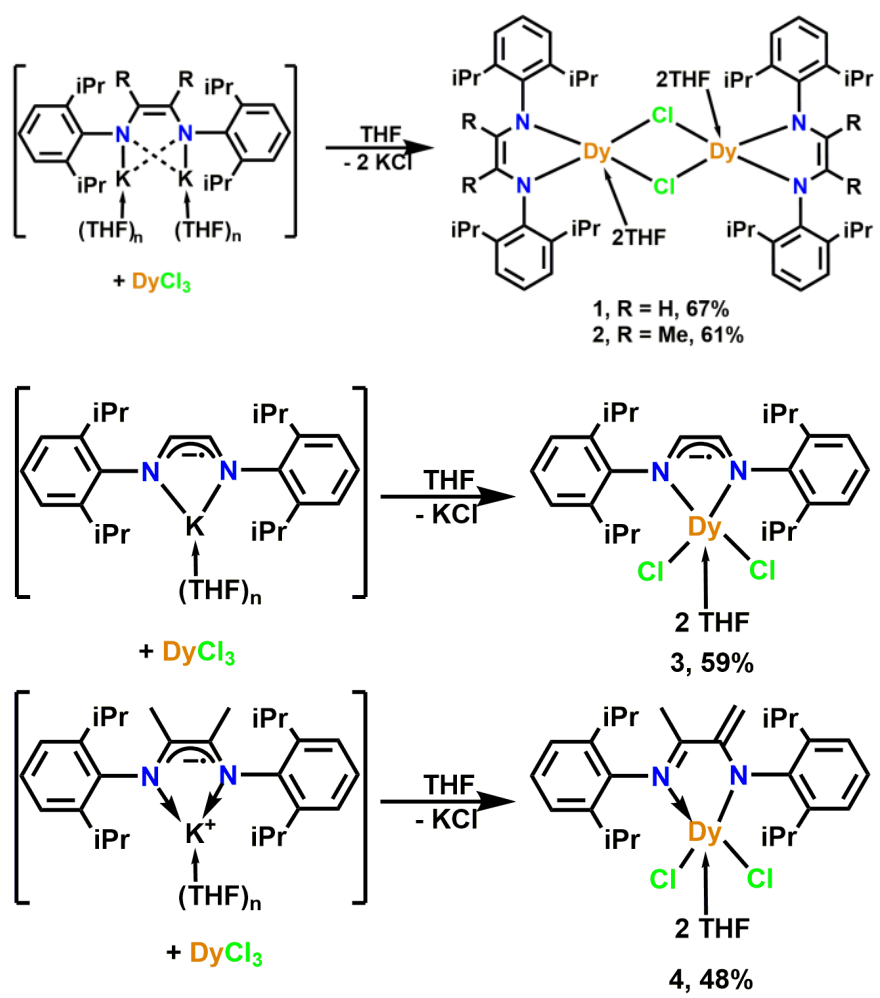

Scheme 1. Synthesis of complexes 1-4.

The outcomes of the salt-metathesis reactions of $\mathrm{DyCl}_{3}$ with equimolar amount of the radical-anionic adducts of diazabutadienes with potassium $\mathrm{K}^{+} /\left(\mathrm{DAD}^{2 \mathrm{R}}\right)^{-} \cdot(\mathrm{THF})_{\mathrm{n}}(\mathrm{R}=\mathrm{H}, \mathrm{Me})$ proved to be dramatically influenced by the nature of the imino carbons' substituents of the parent diazabutadienes. When the diazabutadiene with a $\mathrm{CH}-\mathrm{CH}$ backbone $\left(D A D^{2 \mathrm{H}}\right)$ was used, the reaction afforded the expected dichloro mononuclear complex $\left[\mathrm{Dy}\left(\mathrm{DAD}^{2 \mathrm{H}}\right) \mathrm{Cl}_{2}(\mathrm{THF})_{2}\right]$ (3) coordinated by a radical-anionic $D A D^{2 \mathrm{H}-}$. ligand (Scheme 1 ). In the case of the dimethyl containing analogue $\left(D A D^{2 M e}\right)$, the reaction of $\mathrm{K}^{+} / \mathrm{DAD}^{2 \mathrm{Me}-}$. with $\mathrm{DyCl}_{3}$ under analogous conditions unexpectedly results in the formation of $\left[\mathrm{Dy}\left(\mathrm{DAD}^{2 \mathrm{Me}}\right) \mathrm{Cl}_{2}(\mathrm{THF})_{2}\right]$ complex containing the amido-imino ligand [2,6$\left.i \mathrm{Pr}_{2} \mathrm{C}_{6} \mathrm{H}_{3} \mathrm{~N}=\mathrm{C}(\mathrm{Me}) \mathrm{C}\left(=\mathrm{CH}_{2}\right) \mathrm{NC}_{6} \mathrm{H}_{3} i \mathrm{Pr}_{2}-2,6\right]$ (4) (Scheme 1). The formation of this latter results from the activation of the $\mathrm{C}-\mathrm{H}$ bond of one of the methyl groups of the $D A D^{2 M e}$ backbone. The reactions were carried out in THF solution at room temperature. After separation of $\mathrm{KCl}$, extraction of the reaction product with toluene and subsequent recrystallization from THF/hexane mixture complexes $\mathbf{3}$ and $\mathbf{4}$ were isolated as red crystals in 59 and $48 \%$ yield, respectively.

\section{Crystal Structures}

The molecular structures of complexes $\mathbf{1}$ and $\mathbf{2}$ were established by X-ray diffraction studies and are depicted in Fig. 1. The crystal data and structure refinement details are given in Table S1 (see ESI). The compounds $\mathbf{1}$ and $\mathbf{2}$ are dinuclear dysprosium complexes crystallizing in the orthorhombic $\mathrm{Pbca}$ 
and monoclinic $P 2_{1} / n$ space groups, respectively (Table S1). For both complexes, there is a unique $\mathrm{Dy}^{3+}$ site in the asymmetric unit leading to a centrosymmetric dinuclear core. The dinuclear unit results from connections between the $\mathrm{Dy}^{3+}$ ions ensured by $\mu^{2}$-chloro ligands with relatively long $\mathrm{Dy}-\mathrm{Cl}$ distances of 2.7109(4)/2.7617(4) $\AA$ and 2.7365(5)/2.8353(5) $\AA$ for 1 and 2, respectively (Table 1 ). Charge considerations and geometrical parameters of NCCN fragments in 1 (N-C: $1.403(2)$,

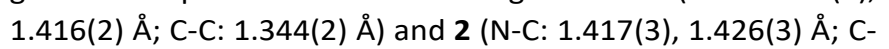
C: $1.373(4) \AA$ ) indicate that the $D A D^{2 R}$ ligands are in a dianionic state. The coordination sphere of the $\mathrm{Dy}^{3+}$ ions in $\mathbf{1}$ and $\mathbf{2}$ is composed by two nitrogens from the DAD ligand, two chlorides and two oxygens from THF resulting in a distorted octahedral geometry. The SHAPE ${ }^{58}$ analysis reveals that the deviation from a perfect octahedral geometry is more pronounced in $\mathbf{2}$ (Table S2), which may be ascribed to the steric hindrance brought by the methyl groups on the $D A D^{2 M e}$ ligand. The two Dy- $\mathrm{N}$ distances in $\mathbf{1}$ have close values (2.243(2), 2.249(2) $\AA$ ) and are slightly longer than in 2, where the Dy-N distances appear somewhat different (2.225(2), 2.252(2) Å, Table 1). In general, the Dy-N bond lengths in 1 and $\mathbf{2}$ are slightly longer than in a related six-coordinated halfsandwich $\mathrm{Dy}^{3+}$ complex [Dy(DAD)Cp*(THF)] (2.189(2), 2.202(2) $\AA) .{ }^{53}$ On the other hand, the Dy-O distances in $\mathbf{1}$ and $\mathbf{2}$ fall in the ranges $2.35(2)-2.400(2)$ and $2.404(2)-2.430(2) \AA$ respectively. Similarly to the previously reported rare-earth complexes coordinated by ene-diamide ligands, the metallacycles in $\mathbf{1}$ and $\mathbf{2}$ are not planar, but are bent along the NN axis: the dihedral angles between NDyN and NCCN planes are $168.0(2)^{\circ}(1)$ and $164.9(2)^{\circ}(2)$. These values are much larger compared to those in the related [Dy(DAD)Cp*(THF)] $\left(141.7(2)^{\circ}\right), \quad\left[\mathrm{Dy}(\mathrm{DAD}) \mathrm{Cp}^{*}\left(\mu^{2}-\mathrm{Cl}\right) \mathrm{Li}(\mathrm{THF})_{3}\right] \quad\left(137.5(2)^{\circ}\right)^{53}$ and $\left[\mathrm{Li}(\mathrm{DME})_{3}\right]\left[\mathrm{Dy}(\mathrm{DAD})_{2}\right]\left(130.4(2)-132.6(2)^{\circ}\right)$ complexes. $^{52}$ The distances between the $\mathrm{Dy}^{3+}$ ion and the carbon atoms of the NCCN fragment in 1 and 2 fall into the range 3.042(2)-3.107(2) $\AA$ and are much longer than in the above mentioned previously reported dysprosium complexes (2.672(3)-2.846(2) $\AA$ ).
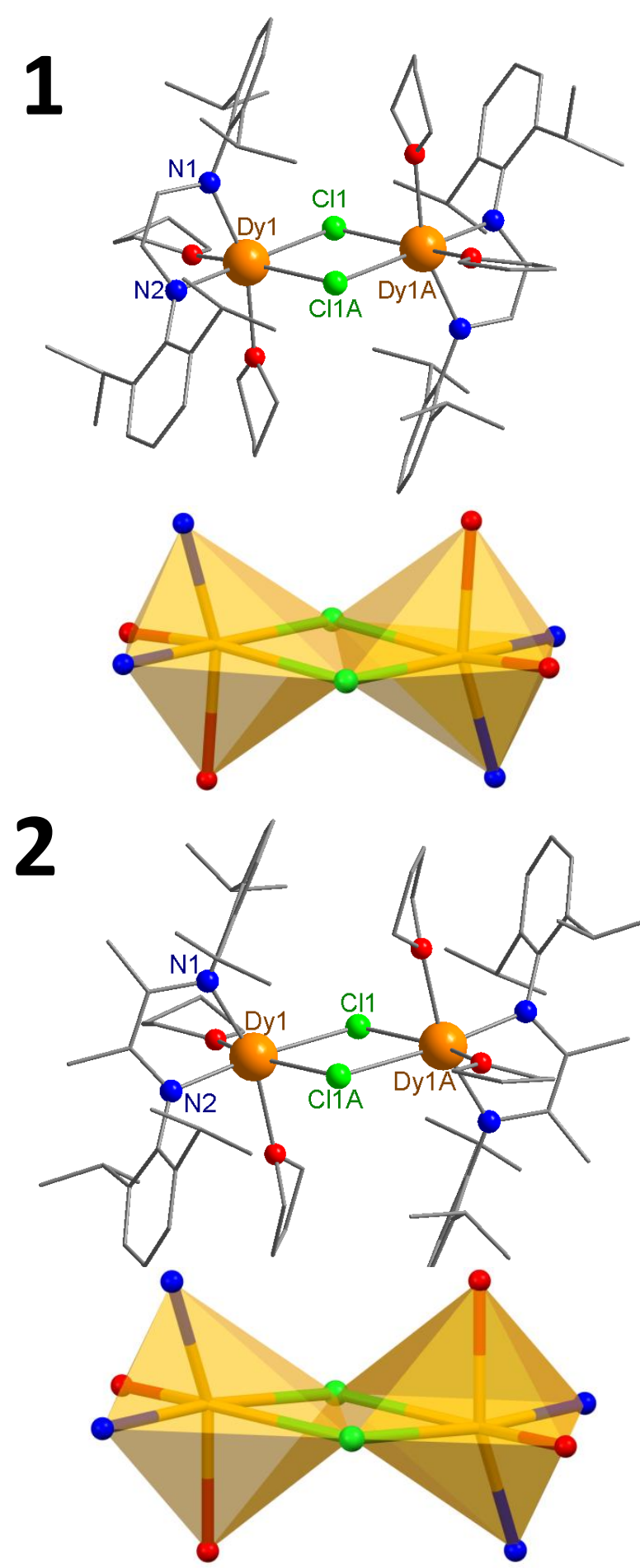

Fig. 1. Molecular structures of $\mathbf{1}$ and $\mathbf{2}$ associated with the dinuclear core showing the coordination polyhedra. Color code: orange $\mathrm{Dy}$, green $\mathrm{Cl}$, red $\mathrm{O}$, blue $\mathrm{N}$, grey $\mathrm{C}$ (hydrogen atoms have been omitted for clarity). The symmetry code for A-labelled atoms is $1-x, 1-y, 1-z$.

Thus, most likely the interaction between the $\mathrm{C}=\mathrm{C}$ fragment and $\mathrm{Dy}^{3+}$ ion does not exist in $\mathbf{1}$ and $\mathbf{2}$ and the coordination mode of the dianionic DAD ligands can be classified rather as $\kappa^{2}-\mathrm{N}, \mathrm{N}$-type than $2 \sigma: \eta^{2}$. Remarkably, the intramolecular Dy-Dy distance of $4.2721(2) \AA$ in 1 is slightly shorter with respect to that of $4.4558(2) \AA$ found in 2 (Table 1 ). The crystal packing analysis (Fig. S1) reveals that the shortest Dy-Dy 
intermolecular distances are equal to $9.6960(2)$ and $11.5267(3)$ Å for $\mathbf{1}$ and $\mathbf{2}$, respectively.

Complexes $\mathbf{3}$ and $\mathbf{4}$ crystallize in the monoclinic space groups $P 2_{1} / n$ and $P 2_{1}$, respectively, and adopt mononuclear structures. Complex $\mathbf{4}$ is isomorphous to the previously published yttrium analogue. ${ }^{55} \mathbf{3}$ exhibits a unique complex in the asymmetric unit, whereas 4 presents two crystallographically independent complexes. The coordination environment of the $\mathrm{Dy}^{3+}$ ion in both samples is, at first glance, similar and is constituted by two nitrogens from a $D A D^{2 R}$ ligand, two THF molecules and two chlorides located in trans fashion giving a six-coordinated geometry (Fig. 2). Simple charge considerations indicate a monoanionic character of the $\mathrm{DAD}^{2 \mathrm{R}}$ ligands.

However, the analysis of the resulting six-coordinated geometries for the $\mathrm{Dy}^{3+}$ site by SHAPE reveals that: i) $\mathbf{3}$ exhibits a distortion from a perfect octahedral geometry similar to that is observed in $\mathbf{1}$ and $\mathbf{2}$; $i$ ) the two dysprosium sites in $\mathbf{4}$ appear quite different in terms of deviation from the octahedral geometry (Table S2). In 3, the $\mathrm{Cl}-\mathrm{Dy}-\mathrm{Cl}$ angle is equal to $160.65(2)^{\circ}$, while it is found much weaker in 4 with values of 145.34(8) and $149.73(6)^{\circ}$ (Table 2). The Dy-Cl distances are comparable in both compounds and are ranging from $2.5757(4)$ to $2.609(2) \AA$. . Additionally, the Dy-O distances in 3 of 2.375(2) and 2.376(2) $\AA$ are found analogous with those involving the DAD ligand, while they appear noticeably longer in 4 with values ranging from $2.400(5)$ to $2.421(5) \AA$.

Table 1: Some relevant crystallographic parameters for $\mathbf{1}$ and $\mathbf{2}$.

\begin{tabular}{|c|c|c|c|c|c|}
\hline $\begin{array}{l}\text { Comp } \\
\text { ound }\end{array}$ & $\begin{array}{c}\text { Dy-N } \\
\text { distances } \\
(\AA ̊)\end{array}$ & $\begin{array}{c}\text { Dy-Cl } \\
\text { distances } \\
(\AA ̊)\end{array}$ & $\begin{array}{l}\text { Dy-Cl- } \\
\text { Dy } \\
\text { angle }^{\circ}\end{array}$ & $\begin{array}{l}\text { Intramolecu } \\
\text { lar Dy-Dy } \\
\text { distance }(\AA)\end{array}$ & $\begin{array}{c}\text { shortest } \\
\text { intermolecu } \\
\text { lar Dy-Dy } \\
\text { distance }(\AA)\end{array}$ \\
\hline 1 & $\begin{array}{l}2.243(2) \\
2.249(2)\end{array}$ & $\begin{array}{l}2.7109(4) \\
2.7617(4)\end{array}$ & $\begin{array}{c}102.64 \\
(2)\end{array}$ & $4.2721(2)$ & $9.6960(2)$ \\
\hline 2 & $\begin{array}{l}2.225(2) \\
2.252(2)\end{array}$ & $\begin{array}{l}2.7365(5) \\
2.8353(5)\end{array}$ & $\begin{array}{c}106.19 \\
(2)\end{array}$ & $4.4558(2)$ & $11.5267(3)$ \\
\hline
\end{tabular}

More importantly, careful analysis of the different crystallographic distances of the $D A D^{2 R}$ ligands points their different redox states. Hence, the $D A D^{2 \mathrm{H}}$ in $\mathbf{3}$ is coordinated to the $\mathrm{Dy}^{3+}$ ion symmetrically: the Dy- $\mathrm{N}$ bond lengths are $2.386(2)$ and 2.381(2) А. The "imino" C-N bond lengths in the DAD ${ }^{2 H}$ ligand are close $(1.331(2)$ and $1.334(2) \AA$ ) and are noticeably longer than the bonds in the parent $\operatorname{DAD}^{2 H}(1.266(3) \AA) .{ }^{59}$ In turn, the $\mathrm{C}-\mathrm{C}$ bond in the diimine fragment of complex 3 $(1.399(3) \AA)$ is significantly shorter than in the neutral free $\operatorname{DAD}^{2 \mathrm{H}}(1.467(5) \AA)$, indicating a partially double bonding due to the delocalization of the negative charge within the NCCN fragment. Thus, the geometry of the NCCN fragment in $\mathbf{3}$ confirms the reduced radical-anionic character of the DAD ligand. As a result, the metallacycle in $\mathbf{3}$ is almost planar with a dihedral angle between NDyN and NCCN planes equal to $174.49(8)^{\circ}$.

In contrast, the chelating $\mathrm{DAD}^{2 \mathrm{Me}}$ in the two complexes in $\mathbf{4}$ coordinates the $\mathrm{Dy}^{3+}$ ion in a non-symmetric way.
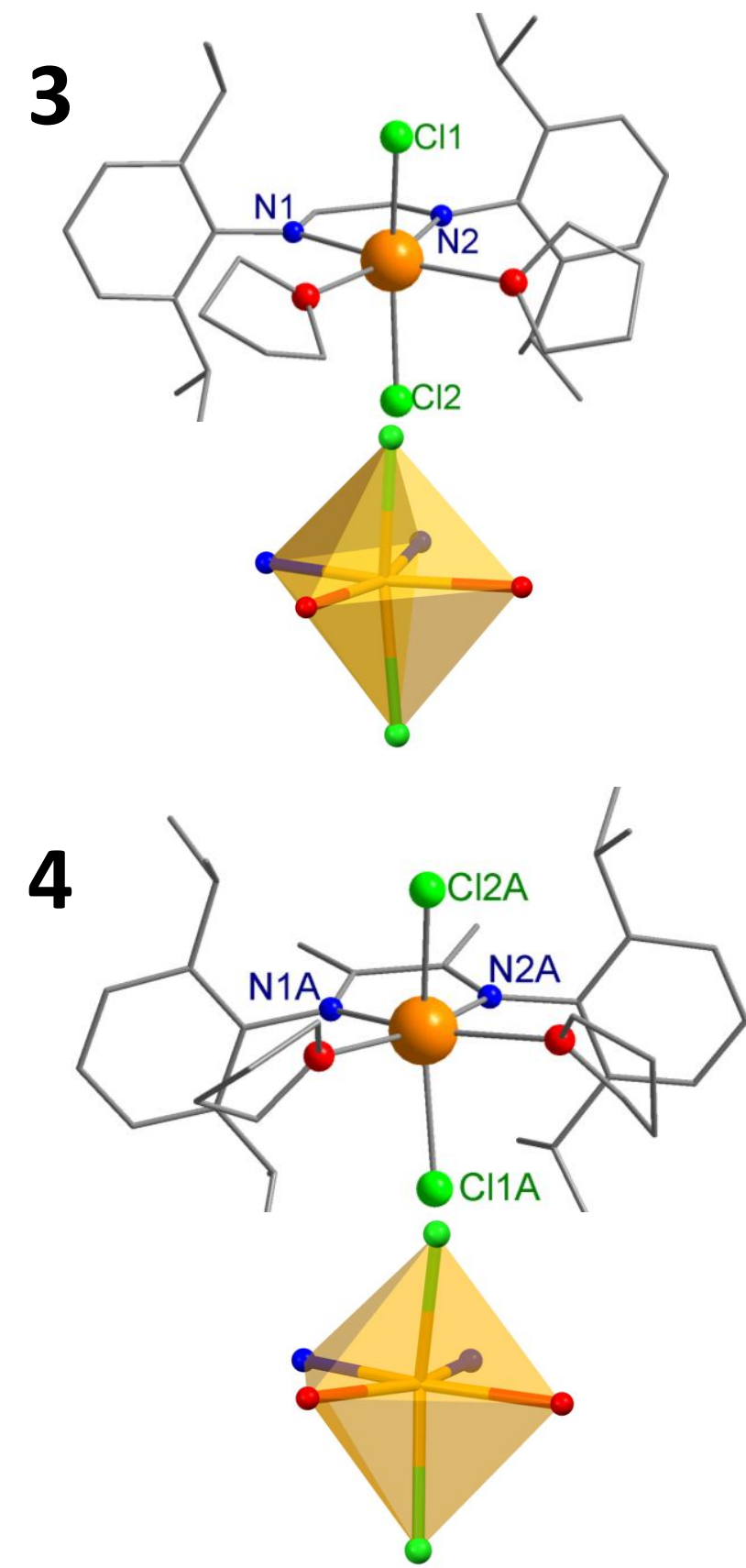

Fig. 2 Molecular structures of $\mathbf{3}$ and one of the crystallographic complexes in $\mathbf{4}$ (Dy1A) associated with the mononuclear core showing the coordination polyhedra. Color code: orange Dy, green $\mathrm{Cl}$, red $\mathrm{O}$, blue $\mathrm{N}$, grey $\mathrm{C}$ (hydrogen atoms have been omitted for clarity).

For the two independent complexes, the Dy1-N1 (2.288(6), $2.298(6) \AA$ ) covalent bond is comparable with the Dy-N bonds in six coordinate bis(amido) dysprosium complex ([2-OMe$\left(\mathrm{C}_{6} \mathrm{H}_{4}\right) \mathrm{NC}(\mathrm{Me}) \mathrm{CHC}(\mathrm{Me}) \mathrm{N}\left(\mathrm{C}_{6} \mathrm{H}_{4}\right)$-OMe-2]Dy $\left(\left(\mathrm{NSiMe}_{3}\right)_{2}\right)_{2}$ (2.296(2) $\AA)),{ }^{60}$ but is somewhat longer than the related bonds in $\mathbf{1}$ and $\mathbf{2}$ (2.225(2)-2.249(2) Å). The second Dy1-N2 bond (2.454(6), $2.462(6) \AA$ ) is however significantly longer compared to the Dy1-N1 and the Dy-N bonds in 3 (2.381(2)-2.386(2) $\AA$ ) and elongated in comparison to related values in $\mathrm{Dy}^{3+}$ complexes containing monoanionic six coordinate $\beta$-diketiminate ligands $\left(\mathrm{LDyCl}_{2}(\mathrm{THF})_{2} \quad\left(\mathrm{~L}=2,4,6-\mathrm{Me}_{3} \mathrm{C}_{6} \mathrm{H}_{2} \mathrm{NC}(\mathrm{Me}) \mathrm{CHC}(\mathrm{Me}) \mathrm{N}-2,4,6-\right.\right.$ $\left.\mathrm{Me}_{3} \mathrm{C}_{6} \mathrm{H}_{2}\right) \quad$ Dy-N 2.337(3), 2.351(3) $\AA^{;} ; \quad$ ([2-OMe$\left.\left(\mathrm{C}_{6} \mathrm{H}_{4}\right) \mathrm{NC}(\mathrm{Me}) \mathrm{CHC}(\mathrm{Me}) \mathrm{N}\left(\mathrm{C}_{6} \mathrm{H}_{4}\right)-\mathrm{OMe}-2\right] \mathrm{Dy}\left(\left(\mathrm{NSiMe}_{3}\right)_{2}\right)_{2} \quad$ Dy-N $2.394(2) \AA) .{ }^{60}$ The $\mathrm{C}-\mathrm{N}$ bonds within the NCCN fragment are 
also noticeably different. The length of one bond (1.366(8), 1.368(9) $\AA$ ) is close to a single $C-N$ bond, while the second one (1.29(2), 1.309(9) $\AA$ ) corresponds to a double $\mathrm{C}=\mathrm{N}$ bond. ${ }^{62}$ The C-C bond length $(1.48(2) \AA)$ is in good agreement with the value measured in the related dichloro yttrium complex $([(2,6-$ $\left.\left.i \mathrm{Pr}_{2} \mathrm{C}_{6} \mathrm{H}_{3}\right) \mathrm{N}=\mathrm{C}(\mathrm{Me}) \mathrm{C}\left(=\mathrm{CH}_{2}\right) \mathrm{N}\left(\mathrm{C}_{6} \mathrm{H}_{3}-2,6-i \mathrm{Pr}_{2}\right)\right] \mathrm{YCl}_{2}(\mathrm{THF})_{2} \quad$ (1.494(6) A)) coordinated by amido-imino DAD ligand. ${ }^{55}$ The $\mathrm{C}-\mathrm{CH}_{3}$ bond length $(1.47(2), 1.49(2) \AA)$ corresponds to a single bond, ${ }^{62}$ while the $\mathrm{C}-\mathrm{CH}_{2}$ distance $(1.37(2), 1.40(2) \AA)$ is indicative of double character of this bond. Thus, the geometric parameters of the $D A D^{2 M e}$ ligand undoubtedly testify its amido-imine nature. This clearly indicates that the DAD ${ }^{2 \mathrm{Me}}$ ligand in $\mathbf{4}$ is in a monoanionic state with a negative charge mainly localised on the $\mathrm{N} 1$ atom.

The shortest intermolecular Dy-Dy distance found in the crystal for $\mathbf{3}$ is relatively short $(7.0021(3) \AA$ ) , while it appears longer in 4 (9.7474(4) Å)(Fig. S2, Table 2).

Table 2: Some relevant crystallographic parameters for $\mathbf{3}$ and $\mathbf{4}$.

\begin{tabular}{|c|c|c|c|c|c|}
\hline \multicolumn{2}{|c|}{ Compound } & $\begin{array}{c}\text { Dy-N } \\
\text { distances }(\AA ̊)\end{array}$ & $\begin{array}{c}\text { Dy-Cl } \\
\text { distances } \\
(\AA ̊)\end{array}$ & $\begin{array}{l}\text { Cl-Dy-Cl } \\
\text { angle }\left({ }^{\circ}\right)\end{array}$ & $\begin{array}{c}\text { shortest } \\
\text { intermolecular } \\
\text { Dy-Dy }^{3} \\
\text { distance }(\AA)\end{array}$ \\
\hline \multicolumn{2}{|c|}{3} & $\begin{array}{l}2.381(2) \\
2.386(2)\end{array}$ & $\begin{array}{l}2.5757(4) \\
2.5811(5)\end{array}$ & $160.65(2)$ & $7.0021(3)$ \\
\hline \multirow{2}{*}{4} & Dy1A & $\begin{array}{l}2.298(6) \\
2.453(6)\end{array}$ & $\begin{array}{l}2.577(2) \\
2.585(2)\end{array}$ & $149.73(6)$ & \multirow{2}{*}{$9.7474(4)$} \\
\hline & Dy1B & $\begin{array}{l}2.288(6) \\
2.462(6)\end{array}$ & $\begin{array}{l}2.579(2) \\
2.609(2)\end{array}$ & $145.34(8)$ & \\
\hline
\end{tabular}

\section{Magnetic Properties}

The static and dynamic magnetic properties of all the obtained complexes were investigated by using a SQUID MPMS-XL magnetometer in the $1.8-300 \mathrm{~K}$ temperature range.

\section{Magnetic properties}

The direct current (dc) magnetic properties are shown in Fig. 3. At room temperature, the experimental $\chi T$ values of 25.74 and $28.07 \mathrm{~cm}^{3}$.K. $\mathrm{mol}^{-1}$ for $\mathbf{1}$ and $\mathbf{2}$, respectively, are in a relatively good accordance with the value of $28.34 \mathrm{~cm}^{3} . K . \mathrm{mol}^{-1}$ expected for two non-interacting $\mathrm{Dy}^{3+}$ ions $(J=15 / 2, g=4 / 3)$ using the free ion approximation (Fig. 3a).

Compound 3 exhibits a room temperature $\chi^{T}$ value of $12.55 \mathrm{~cm}^{3} . \mathrm{K}^{\mathrm{mol}} \mathrm{mol}^{-1}$, which is slightly lower than the expected value of $14.54 \mathrm{~cm}^{3} . \mathrm{K} \mathrm{mol}^{-1}$ for a non-interacting $\mathrm{Dy}^{3+}$ ion and a radical $(S=1 / 2)$. Such fact could be rationalized by the occurrence of antiferromagnetic interactions still operative at room temperature, as frequently observed in other lanthanide/radical complexes. ${ }^{40,63-64}$ Besides, the presence of radical/radical exchange interactions could not be excluded due to the short intermolecular distances between the DAD ${ }^{2 \mathrm{H}}$ ligands. $^{50,65}$ For instance, the shortest intermolecular C-C distance in the crystal is found to be only $3.743 \AA$. The room temperature $\chi^{T}$ value of $13.20 \mathrm{~cm}^{3} \cdot \mathrm{K} \mathrm{mol}^{-1}$ for complex 4 is close to the expected value of $14.17 \mathrm{~cm}^{3} . \mathrm{K} \cdot \mathrm{mol}^{-1}$ expected for a single $\mathrm{Dy}^{3+}$ ion.
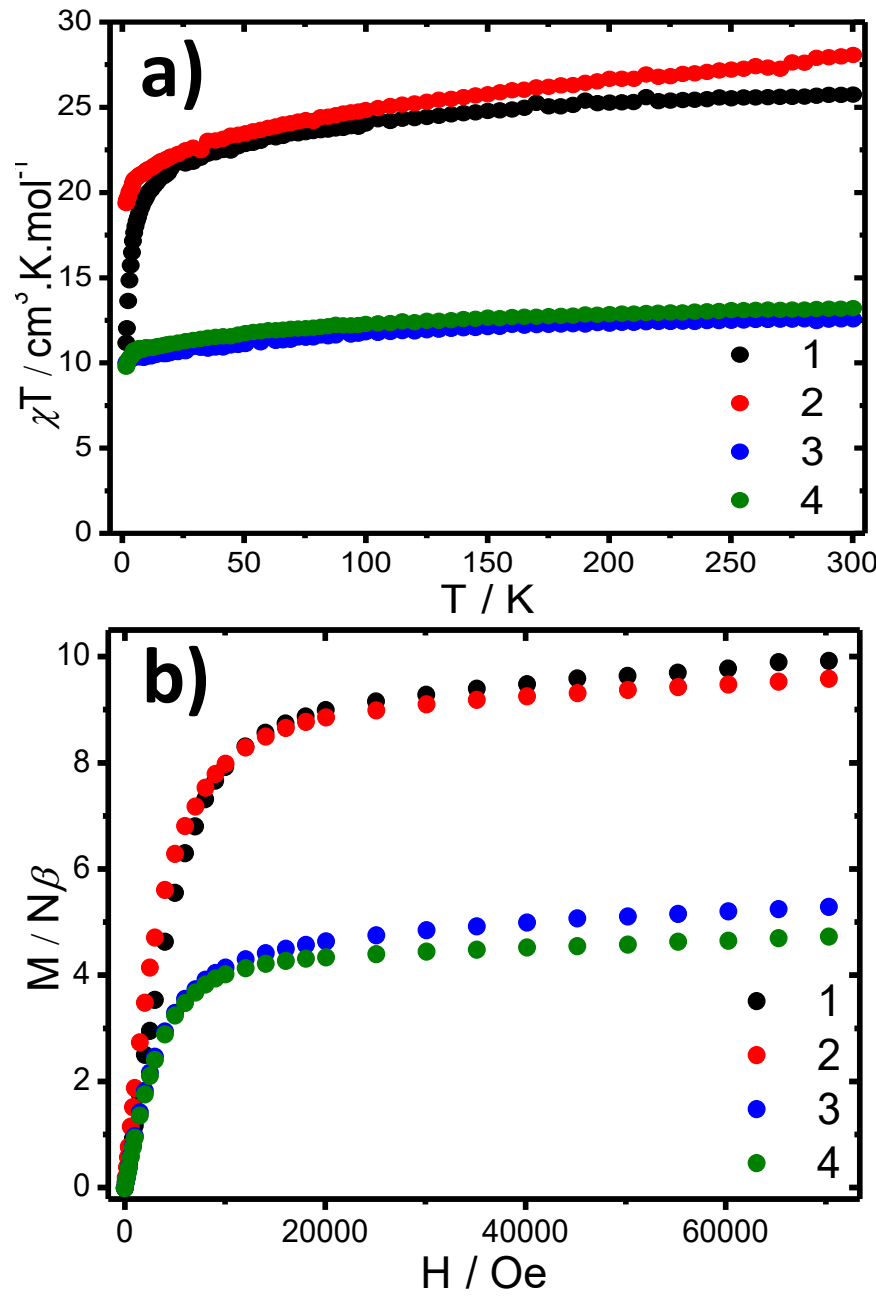

Fig. 3. a) Temperature dependence of $\chi T$ under an applied magnetic field of 1000 Oe for 1-4. b) Field dependence of the magnetization at $1.8 \mathrm{~K}$ for 1-4.

Upon cooling, all the samples exhibit a decrease of $\chi^{T}$ to reach the values of $11.17,19.37,9.97$ and $9.76 \mathrm{~cm}^{3} . \mathrm{K}_{\mathrm{mol}}{ }^{-1}$ for compounds 1, 2, 3 and 4, respectively, which may be ascribed to the thermal depopulation of the $m_{\mathrm{J}}$ levels, inherent to the individual dysprosium centers. Because of this phenomenon, it is difficult for the dinuclear complexes $\mathbf{1}$ and $\mathbf{2}$ to discern the presence of possible antiferromagnetic interactions between the $\mathrm{Dy}^{3+}$ ions. One can however notice a pronounced $\chi T$ decrease below $50 \mathrm{~K}$ for $\mathbf{1}$ with respect to $\mathbf{2}$ which could be ascribed to a magnetization blocking and/or antiferomagnetic interactions. On the other hand, compound $\mathbf{3}$ and $\mathbf{4}$ shows a very similar trend in their thermal dependence of $\chi T$. Taking into account that the presence of strong radical/Dy ${ }^{3+}$ interactions would cause a noticeable difference, such results suggest the occurrence of relatively weak dysprosium/radical interactions. The field dependences of the magnetization measured at $1.8 \mathrm{~K}$ exhibit the classical shape observed for similar $\mathrm{Dy}^{3+}$ complexes with values of $9.91,9.57,5.28$, and 4.72 $N \beta$ for compounds 1 to $\mathbf{4}$, respectively (Fig. 3b).

\section{AC Magnetic properties}

The dynamic behaviour of all compounds was then investigated by alternating current (ac) magnetometry in order 
to probe the occurrence of a slow relaxation of the magnetization arising from a SMM behaviour.

\section{Relaxation in zero dc-field}

Under a zero dc-field, all the compounds exhibit a significant out-of-phase susceptibility ( $\left.\chi^{\prime \prime}\right)$ component indicating the occurrence of a slow relaxation of the magnetization (Fig. 4-5, Fig. S3).

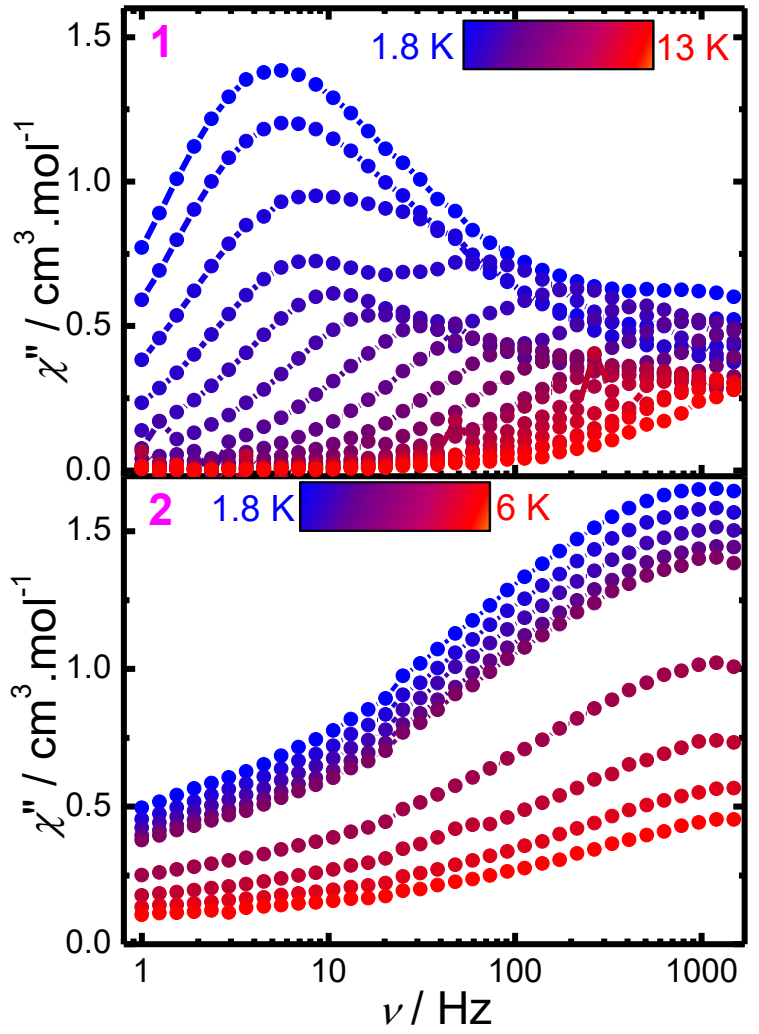

Fig. 4. Frequency dependence of the out-of phase ( $\left.\chi^{\prime \prime}\right)$ susceptibilities for $\mathbf{1}$ and $\mathbf{2}$ under a zero dc-field.

The frequency dependence of the out-of-phase susceptibilities under a zero dc-field reveals however dramatic differences between the investigated samples.

Firstly, comparison between the two dinuclear complexes 1 and $\mathbf{2}$ could be carried out: while $\mathbf{2}$ exhibits a broad signal without a clear maximum, $\mathbf{1}$ shows an intricate temperature dependence with the presence of two maxima for some temperatures (Fig. 4). This is further confirmed by the thermal dependence of the ac susceptibilities (Fig. S4) and the ColeCole plots (Fig. S5). Fig. 4 shows that for 1 and up to $3.4 \mathrm{~K}$, a broad maximum accompanied with a plateau could be observed in the frequency dependence of $\chi^{\prime \prime}$. Yet, for greater temperature, two close maxima are observed in the range 4.2$8.2 \mathrm{~K}$ before one peak shifts out of the available frequency range. Hence, the related Cole-Cole plots for 1 were fitted with a sum of two modified Debye functions, ${ }^{66}$ but taking into account distinct temperature ranges (Table S3-S4). Analyzing the origin of the two relaxation process in lanthanide SMMs is not straightforward. As there is a unique crystallographic dysprosium(III) ion in the asymmetric unit, one possible explanation might be related to the presence of a crystallographic disorder on one coordinated THF. Due to the absence of a clear maximum for $\mathbf{2}$ owing to the broadness of the signal, it was not possible to achieve a pertinent fit of the Cole-Cole plots. This however points out a wide distribution of the relaxation times.

In the same way than for $\mathbf{2}$, the mononuclear complexes $\mathbf{3}$ and 4 show very broad $\chi^{\prime \prime}$ signals in the 1.8-4.0 $\mathrm{K}$ temperature range with the presence of discernible maxima (Fig. 5). The Cole-Cole plots for 3 and $\mathbf{4}$ (Fig. S5) could be fitted with a generalized Debye model giving large values of the $\alpha$ parameters ( $\alpha \approx 0.4$, Table S5-S6) confirming the wide distribution of the relaxation times expected from the frequency dependence of $\chi^{\prime \prime}$. At the exception that the maxima of $\chi^{\prime \prime}$ are seen for weaker frequency values for $\mathbf{3}$, the radical state of the ligand seems to moderately influence the relaxation with respect to 4 . This suggests that the relaxation is dominated by the single-ion anisotropy of the $\mathrm{Dy}^{3+}$ ion.

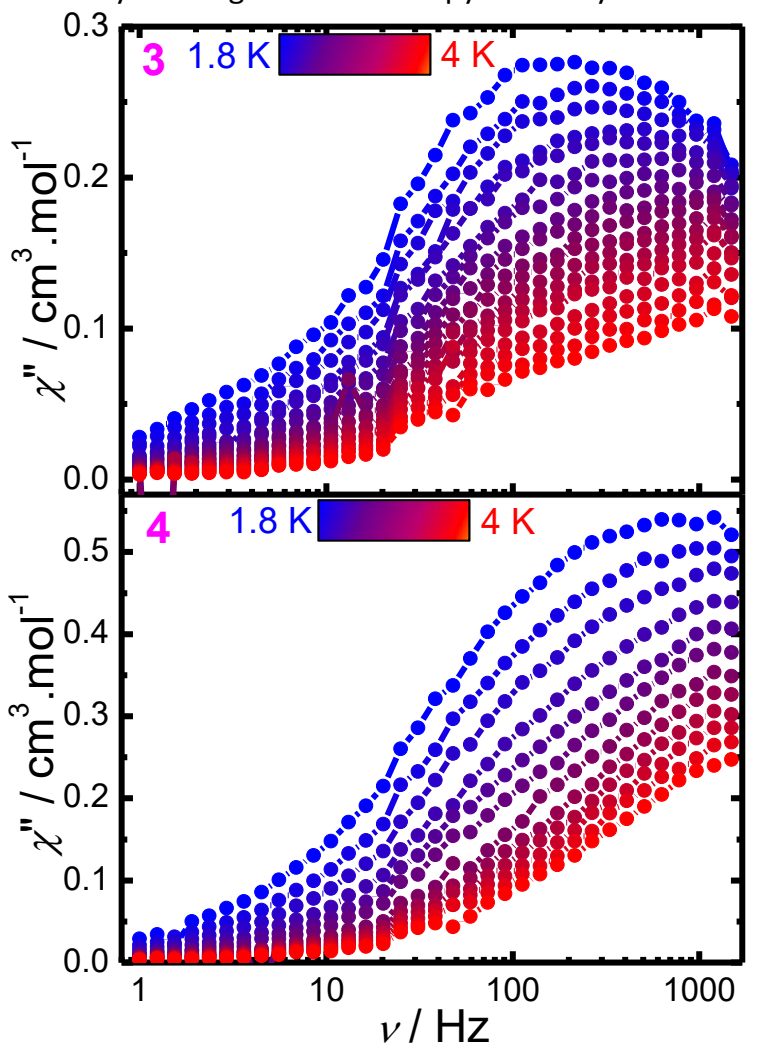

Fig. 5. Frequency dependence of the out-of phase $\left(\chi^{\prime \prime}\right)$ susceptibilities for $\mathbf{3}$ and $\mathbf{4}$ under a zero dc-field.

Further details into the dynamics of the relaxation could be obtained from studying the temperature dependence of the relaxation time, $\tau$, albeit it was not possible to extract a value of the relaxation time for compound $\mathbf{2}$ due to the absence of a clear maximum. For the three other compounds, the $\ln \tau$ vs. $T^{-1}$ plot is shown in Fig. 6 . In contrast to compounds $\mathbf{3}$ and $\mathbf{4}$, the main relaxation process for $\mathbf{1}$ exhibits a pseudo-linear part at high temperature that might suggest a contribution from a thermally activated relaxation. At low temperatures for $\mathbf{1}$, the relaxation time becomes temperature independent, pointing out the occurrence of a QTM. 
Hence, attempts to model the thermal dependences of the relaxation time was performed using the following equation: $\tau$ ${ }^{-1}=\tau_{0}^{-1} \exp (-\Delta / k T)+C T^{n}+\tau^{-1}$ QTM (Eq. 1). ${ }^{67}$ The first term accounts for a thermally activated process, while the second and third ones stand for two-phonon Raman and QTM, respectively. For the dinuclear complex 1, the obtained Raman exponent of 5.2 is close to the theoretical value of 5 observed for some Kramers ions. ${ }^{67}$ Hence, the magnetization relaxes through the combination of these three different processes (Table 3). However, and giving the weak anisotropy barrier obtained from the mathematical fitting for 1, the Raman process most likely dominates the relaxation dynamics. Thus, it was also possible to perform the fitting by taking into account solely a Raman and QTM processes (Table S7). This suggests that an important overlap between Orbach and Raman processes occurs in this system within the temperature range investigated. Although it is possible to perform a fitting of the thermal dependence of the relaxation time for $\mathbf{3}$ and $\mathbf{4}$ using Eq. 1, the very small values of the obtained anisotropic barriers, $\Delta$, strongly suggest the lack of a thermally activated relaxation, as pointed out by the absence of a clear linear part on the $\ln \tau$ vs. $T^{-1}$ plot (Fig. 6). As a consequence, the fitting was performed only taking into account a Raman process, $\tau^{-1}=C T^{n}$ (Eq. 2). For both complexes, the low values of the $n$ exponent suggests the presence of acoustic phonons (Table 3$)^{68}$

\section{Relaxation in dc fields}

It is well known that the relaxation dynamics in lanthanide SMMs could be severely affected by the presence of a magnetic field, which shortcut the QTM. Thus, the field dependence of the ac susceptibilities was measured for all samples (Fig. S6). At the exception of complex 3, applying dc fields induce significant changes in the profile of the ac susceptibly components. Due to the occurrence of broad signals and/or the presence of two relaxation processes, only the field dependence of the relaxation time for compound 4 could be satisfactorily modelled with the following equation, $\tau$ ${ }^{-1}=D H^{4} T+B_{1} /\left(1+B_{2} H^{2}\right)+K$ (Eq. 3), for which the first term accounts for the direct process (for Kramers-ion), the second one stands for the QTM, while the $K$ constant accounts for the field-independent Raman and thermally activated processes (Fig. S7, Table S8). The optimum dc field that maximizes the relaxation time for $\mathbf{4}$ is estimated at 1000 Oe. For comparison purposes, the same dc field was also utilized for the other complexes.

The ac susceptibilities measured under a 1000 Oe dc field for all samples could be found in Fig. S8 and confirm the presence of two relaxation processes for $\mathbf{1}$ at low temperature. Estimation of the relaxation time could be achieved by fitting of the Cole-Cole plots (Fig. S9, Table S9). The temperature dependence of the relaxation time could be only fitted with a thermally activated and Raman process, considering that a direct process is inoperative under this weak dc fields. The obtained value of $\Delta$ (Table 2 ) is close to that obtained under a zero-field, taking into account the uncertainties on the fitting. Despite a weaker coefficient correlation fit, it appears also possible to fit the data considering only a Raman process (Table S7).
Table 3: Fit parameters of the temperature of the relaxation time using Eq. 1 or Eq. 2.

\begin{tabular}{|c|c|c|c|c|c|}
\hline Compound & $\Delta\left(\mathrm{cm}^{-1}\right)$ & $\tau_{0}(\mathrm{~s})$ & $n$ & $\begin{array}{c}C \\
\left(\mathrm{~s}^{-1} . \mathrm{K}^{-n}\right)\end{array}$ & $\tau_{\text {QTM }}(\mathrm{s})$ \\
\hline $\mathbf{1}(0 \mathrm{Oe})$ & $72 \pm 5$ & $\begin{array}{c}(7 \pm 3) \times \\
10^{-8}\end{array}$ & $5.2^{*}$ & $\begin{array}{c}0.0090 \pm \\
0.0008\end{array}$ & $\begin{array}{c}0.04 \pm \\
0.03\end{array}$ \\
\hline $\mathbf{1}(1000$ Oe) & $56 \pm 9$ & $\begin{array}{c}(6 \pm 4) \times \\
10^{-7}\end{array}$ & $5.5^{*}$ & $\begin{array}{c}0.004 \pm \\
0.001\end{array}$ & - \\
\hline $\mathbf{3}(0 \mathrm{Oe})$ & - & - & $\begin{array}{c}2.28 \pm \\
0.05\end{array}$ & $371 \pm 23$ & - \\
\hline $\mathbf{4}(0 \mathrm{Oe})$ & - & - & $\begin{array}{c}1.6 \pm \\
0.1\end{array}$ & $\begin{array}{c}1528 \pm \\
222\end{array}$ & - \\
\hline $\mathbf{4}(1000$ Oe) & - & - & $\begin{array}{c}5.6 \pm \\
0.1\end{array}$ & $0.7 \pm 0.1$ & - \\
\hline
\end{tabular}

*fixed parameter

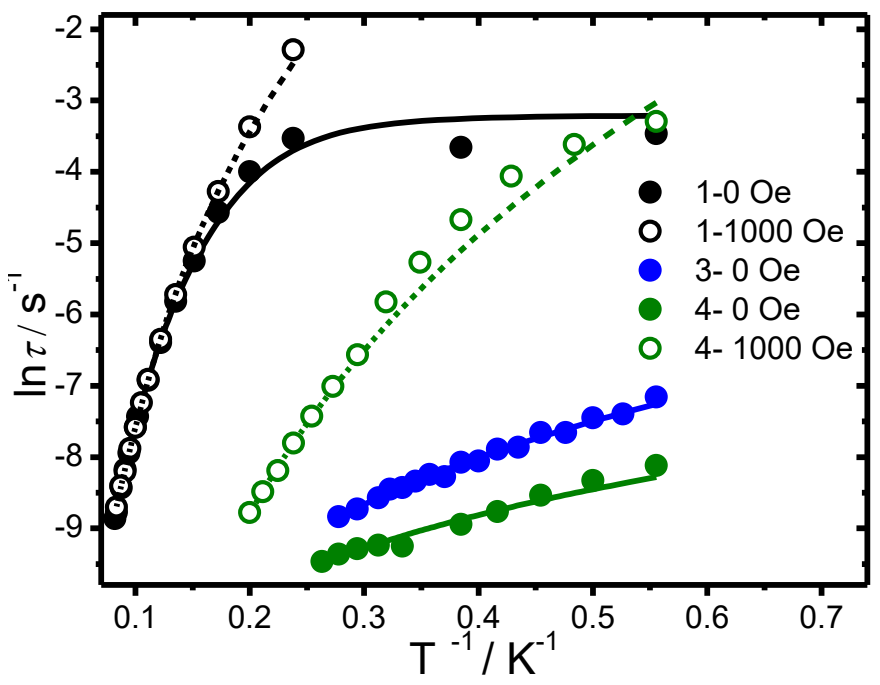

Fig. 6. Temperature dependence of the relaxation time using the ac susceptibility data at $0 \mathrm{Oe}$ and $1000 \mathrm{Oe}$. The solid (0 Oe) and dashed (1000 Oe) lines represent the fit.

As regards 2, and similarly than for the zero-field data, the shape and position of the out-of-phase signal dependence is barely independent of the temperature (Fig. S8), while the Cole-cole plots (Fig. S9) could not be satisfactory fitted confirming a wide distribution of relaxation processes.

For sample 3, applying a dc field creates the appearance of a broad second relaxation process at low frequencies in the out-of-phase component (Fig. S8). No maxima could be discerned, precluding the extrapolation of relevant relaxation time values. In contrast to the zero-field data, a clear maximum in the frequency dependence of $\chi^{\prime \prime}$ could be observed under applying a dc magnetic field for complex 4 (Fig. S8). However, the Cole-Cole plots (Fig. S9) reveals the presence of a second process at low temperatures. These plots were fitted with the sum of two modified Debye functions $(\alpha<$ 0.25 ; Table S10). The fitting the temperature dependence of $\tau$ for 4 was performed with Eq. 2 (Table 3). It indicates that the relaxation proceeds with a Raman process. Introduction of a direct process did not improve the fitting. Thus, the poor fitting may be explained by the presence of a second relaxation process, as evidenced on the Cole-Cole plots.

\section{Magneto-structural correlations}


All the samples investigated in this study exhibit a zero-field relaxation, but different relaxation dynamics. Hence, this series constitute an interesting case to study the influence of the intramolecular $\mathrm{Dy}^{3+}-\mathrm{Dy}^{3+}$ interactions through chloro ligand in dinuclear complexes, the impact of DAD's substituent groups, the influence of radical-Dy ${ }^{3+}$ interactions.

Firstly, a comparison between the two dinuclear complexes 1 and 2 could be performed. These complexes only differ by the nature of the substituent on the dianionic DAD ${ }^{2 R}$ ligand $(H$ vs. Me). While the Dy- $\mathrm{N}$ distances are slightly shorter in $\mathbf{2}$, an introduction of the methyl groups creates an enhanced distortion of the octahedral geometry as evidenced by the SHAPE analysis. Besides, using the DAD ${ }^{2 M e}$ gives a very broad signal in the out-of-phase susceptibility component, precluding an in-depth analysis of the relaxation dynamics. Although not directly comparable, we previously observed such broad signals in dysprosium heteroleptic and homoleptic complexes based on the same $D A D^{2 M e}$ ligand. ${ }^{53-54}$ We also note that for $\mathbf{1}$, the relaxation dynamics is most likely dominated by a Raman process as we recently evidenced recently on homoleptic complexes based on DAD ligands. ${ }^{52,54}$ Unfortunately, it turns out that connecting the $\mathrm{Dy}^{3+}$ ions through chloro-bridges does not rigidify the structure to prevent the Raman relaxation. Further details could be also obtained by analysing the direction of the anistropic axis of the ground state doublet from electrostatic considerations by using the Magellan software. ${ }^{69}$ A negative charge was ascribed on each nitrogen of the $D A D^{2 R}$ ligands. Due to the centrosymmetric nature of the complexes, the two anisotropic axes are found collinear (Fig. $\mathrm{S} 10)$. Despite two short Dy- $\mathrm{N}$ distances, the anisotropic axes do not pass through the barycentre of the $D A D^{2 R}$ ligands. In contrast, these axes are almost collinear to the N2-Dy-Cl1 sequence, which exhibits almost a linear angle of 178.92 and $172.73^{\circ}$ for 1 and 2 , respectively. Remarkably, the complementary $\mathrm{N} 1-\mathrm{Dy}-\mathrm{Cl} 1 \mathrm{~A}$ string is far to be linear with values of 105.73 and $103.02^{\circ}$ for $\mathbf{1}$ and $\mathbf{2}$, respectively. Thus, the possibility to align the anisotropic axis with two negatively charged atoms ( $\mathrm{N} 2$ and $\mathrm{Cl} 1$ ) with a quasi-linear angle prevails. On the other hand, the deviation of the anisotropic axis with respect to the N2-Dy-Cl1 sequence is more pronounced for 2 . Hence, the Dy-axis-N1 and Dy-axis-Cl1 angles equal to 18.23 and $21.82^{\circ}$ in 2 may be compared with those of 14.08 and $20.41^{\circ}$ for 1 . This could explain the better magnetic features of 1. Moreover, the introduction of Me groups also induces an increase of the Dy-Dy intramolecular distance by about $0.18 \AA$ associated with slightly longer Dy-Cl distances, which could cause dramatic differences in the strength of both, dipolar or/and exchange interactions. ${ }^{39}$ For comparison, it was recently proposed in a dichloride-bridged dysprosium dinuclear complex with a slightly greater Dy-Dy intramolecular distance of $4.51 \AA$, that the combination of both, dipolar and exchange interactions have to be taken into account to explain the occurrence of an exchange-bias effect. ${ }^{38}$

Secondly, the mononuclear complexes $\mathbf{3}$ and $\mathbf{4}$ could be also compared. In that case, the change in the substituent of the monoanionic DAD induces a different redox state of the ligand. Thus, while in $\mathbf{3}$ the $D A D^{2 \mathrm{H}}$ is in a radical monoanionic state, the $D A D^{2 M e}$ ligand in $\mathbf{4}$ is solely monoanionic, as clearly evidenced from the X-Ray analysis. Unexpectedly, the zerofield relaxation of the two systems is found relatively similar. This suggests that it is mainly dominated by the single-ion anisotropy of the dysprosium ion, rather than a coupled state involving the radical for $\mathbf{3}$. Analogous observations have also been made in weakly exchange systems based on bipyrimidyl, pyridyl-pyrazine or iminopyridine ligands. ${ }^{46-47,50}$ Both, 3 and $\mathbf{4}$ exhibit very broad signals of $\chi^{\prime \prime}$ with a dynamic dominated by a Raman process. An evaluation of the anisotropic axes direction was carried out with the Magellan software by assuming a negative charge on only one nitrogen atom (N1A or N1B) of $D A D^{2 M e}$ for 4 , whereas a single negative charge was delocalized on each atoms of the NCCN fragment of DAD ${ }^{2 \mathrm{H}}$ for complex 3. For the latter, several distributions of the negative charge were investigated by considering either identical or different partial charges on the carbons and nitrogens, respectively (Fig. S11). This however systematically leads to an orientation of the axis towards the barycentre of the $D A D^{2 H}$ ligand. In contrast, the absence of delocalization on the $D A D^{2 \mathrm{Me}}$ ligand for 4 results in an electrostatic contribution imposed by the two trans chloride ions (Fig. S12). The strong deviation from the linearity of the $\mathrm{Cl}-\mathrm{Dy}-\mathrm{Cl}$ arrangement for the two nonequivalent complexes in 4 (149 and $145^{\circ}$ ) induces a deviation of the anisotropic axis along this sequence. For both complexes $\mathbf{3}$ and $\mathbf{4}$, the presence of negatively charged moieties $\left(\mathrm{Cl}^{-}\right.$or $\left.\mathrm{DAD}^{2 \mathrm{Me}}\right)$ in the equatorial plane should induce a pronounced decrease in the axiality, explaining the relatively modest SMM features. At the opposite, the relaxation in the presence of a dc field is found poles apart between the mononuclear complexes $\mathbf{3}$ and $\mathbf{4}$. The reasons for such differences appear difficult to rationalize but the very comparable coordination environments of the two systems suggest that this may involve the different redox states of the DAD ligands. It would be therefore tempting to propose that application of a dc field modifies the exchange interactions involving the radical in $\mathbf{3}$ and resulting in a complex behaviour. In comparison, the usual field-induced shortcut of the QTM is observed for 4 . Such feature appears particularly promising for tuning the SMMs features by playing with the ligand state.

Lastly, both mononuclear and dinuclear systems could be weigh against. The dinuclear complex 1 exhibits clearly the best slow relaxation features of the four investigated systems. As expected from simple electrostatic considerations, the doubly negative charge character of the $D A D^{2 R}$ ligands associated with short Dy- $\mathrm{N}$ distances in $\mathbf{1}$ and $\mathbf{2}$ implies that the direction of the anisotropic axis is mainly imposed by this ligand and the direction involves a linear $\mathrm{N}-\mathrm{Dy}-\mathrm{Cl}$ arrangement. For 3 , the decrease of the negative charge of the radicalmonoanionic $\mathrm{DAD}^{2 \mathrm{H}}$ ligand is balanced by the delocalization on the NCCN fragment. Conversely, the absence of charge delocalization for 4 greatly reduce the $D A D^{2 M e}$ influence implying that the orientation of the anisotropic axis is now imposed by the two trans chloride ions located at a quite long distance to the Dy centre. Moreover, the presence of magnetic interactions in $\mathbf{1}$ between the dysprosium ions does not provide a detrimental effect on the slow relaxation. 


\section{Conclusions}

One of the main outcomes of this work is that the redox-active character of the $D A D^{2 R}$ ligands could be leveraged to design dysprosium SMMs. Hence, a series of heteroleptic dysprosium SMMs based on chloro/DAD ${ }^{2 R}$ ligands has been described. Depending on the experimental conditions and the nature of the substituent borne by the $D A D^{2 R}$ ligands, four different complexes differing from their nuclearity and different $D A D^{2 R}$ redox states have been obtained. Using dianionic $D A D^{2 R}$ ligands affords the formation of chloro-bridged dinuclear complexes 1 and 2. On the other hand, two mononuclear complexes $\mathbf{3}$ and $\mathbf{4}$ with two terminal axial chloride ligands and different DAD redox states (radical monoanionic or monoanionic) have been obtained depending on the nature of the substituent ( $\mathrm{H}$ vs. Me).

Remarkably, the four reported compounds exhibit a zerofield slow relaxation of the magnetization, but rather divergent dynamics. In all cases, an intricate relaxation is observed with the presence of broad signals or several relaxation processes. Complex 1, clearly showing the most interesting magnetic features, constitutes an interesting example of a dinuclear complex with a non-detrimental effect of magnetic coupling between the dysprosium centers, although a strong Raman process is involved. We found that changing the DAD's substituent affects the slow relaxation features.

Mononuclear complexes $\mathbf{3}$ and $\mathbf{4}$ with different DAD state show a relaxation dynamic also dominated by a Raman process. Despite different orientation of their anisotropic axes, the presence of negatively charged moieties in the equatorial plane explains their modest SMM behaviour. Furthermore, it turns out the presence of a radical monoanionic $D A D^{2 \mathrm{H}}$ state in 3 does not strongly affect the zero-field relaxation, most likely due to very weak radical-Dy interactions. Yet, comparison with complex 4 , based on a monoanionic $\mathrm{DAD}^{2 \mathrm{Me}}$ ligand, indicates that the situation appears totally different when a dc field is applied. Due to comparable coordination environment, this effect is certainly caused by the different redox states of the ligand, opening tremendous possibilities for tweaking the SMM properties. The great tunability of the DAD ligands in terms of steric and electronic features holds great promises for the design of SMM.

\section{Experimental}

\section{Materials and Methods}

All operations were carried out under an argon atmosphere using Schlenk techniques or in nitrogen filled glovebox. THF and toluene were purified by distillation from sodium/benzophenone ketyl and degassed thoroughly. Hexane was dried by distillation from sodium/triglyme and benzophenone ketyl prior to use. $\mathrm{DyCl}_{3}{ }^{70}$ and $\operatorname{DAD}^{2 \mathrm{R}}(2,6-$ $\left.i \operatorname{PrC}_{6} \mathrm{H}_{3}-\mathrm{NC}(\mathrm{R}) \mathrm{C}(\mathrm{R}) \mathrm{NC}_{6} \mathrm{H}_{3} i \mathrm{Pr}-2,6\right)(\mathrm{R}=\mathrm{H}, \mathrm{Me})^{71}$ were prepared according to literature procedures. Lanthanide metal analysis was carried out by complexonometric titration. ${ }^{72}$ IR spectra were recorded as Nujol mulls on a Bruker-Vertex 70 spectrophotometer. The $\mathrm{C}, \mathrm{H}, \mathrm{N}$ elemental analyses were performed in the microanalytical laboratory of the G. A. Razuvaev Institute of Organometallic Chemistry.

Synthesis of $\left[\mathrm{Dy}\left(\mathrm{DAD}^{2 \mathrm{H}}\right)\left(\mu^{2}-\mathrm{Cl}\right)(\mathrm{THF})_{2}\right]_{2}(\mathbf{1})$. A solution of $\mathrm{K}_{2}[2,6-$ $\left.i \mathrm{Pr}_{2} \mathrm{C}_{6} \mathrm{H}_{3} \mathrm{NC}(\mathrm{H}) \mathrm{C}(\mathrm{H}) \mathrm{NC}_{6} \mathrm{H}_{3} i \mathrm{Pr}_{2}-2,6\right]$ (THF) $)_{\mathrm{n}}$ in situ obtained from 2,6-iPr ${ }_{2} \mathrm{C}_{6} \mathrm{H}_{3} \mathrm{NC}(\mathrm{H}) \mathrm{C}(\mathrm{H}) \mathrm{NC}_{6} \mathrm{H}_{3} i \mathrm{Pr}_{2}-2,6$ (0.70 g, $1.86 \mathrm{mmol}$ ) and $\mathrm{K}$ shavings ( $0.14 \mathrm{~g}, 3.73 \mathrm{mmol}$ ) in $30 \mathrm{~mL}$ of THF was slowly added to a suspension of $\mathrm{DyCl}_{3}(0.50 \mathrm{~g}, 1.86 \mathrm{mmol})$ in THF $(5 \mathrm{~mL})$ at room temperature. The reaction mixture was stirred for $12 \mathrm{~h}$ at ambient temperature. The volatiles were removed in vacuum and the solid residue was extracted with toluene (40 $\mathrm{mL}$ ). The toluene extract was filtered, toluene was evaporated in vacuum. Recrystallization of the resulting solid from $\mathrm{THF} /$ hexane mixture at $20^{\circ} \mathrm{C}$ afforded red crystals of $\mathbf{1}(0.89 \mathrm{~g}$, $67 \%$ yield). Elemental analysis calcd. (\%) for $\mathrm{C}_{68} \mathrm{H}_{104} \mathrm{Cl}_{2} \mathrm{Dy}_{2} \mathrm{~N}_{4} \mathrm{O}_{4}$ $\left(1438.60 \mathrm{~g} \cdot \mathrm{mol}^{-1}\right)$ : C, 56.82; H, 7.29; Dy, 22.61; N, 3.90; found (\%): C, 56.51; H, 7.53; Dy, 22.83; N, 4.09. IR (Nujol, KBr) v/ $\mathrm{cm}^{-1}$ : $2091(\mathrm{~m}), 1912(\mathrm{~m}), 1852(\mathrm{~m}), 1792(\mathrm{~m}), 1706(\mathrm{~m}), 1659(\mathrm{~m})$, 1585 (s), 1564 (s), 1433 (s), 1358 (s), 1336 (m), $1311(\mathrm{~s}), 1250$ $(\mathrm{s}), 1204(\mathrm{~s}), 1172(\mathrm{~m}), 1157(\mathrm{~m}), 1145(\mathrm{~m}), 1103(\mathrm{~s}), 1057(\mathrm{~s})$, $1055(\mathrm{~s}), 1017(\mathrm{~s}), 951(\mathrm{~m}), 935(\mathrm{~s}), 914(\mathrm{~s}), 883(\mathrm{~s}), 865(\mathrm{~s}), 819$ (s), $801(\mathrm{~s}), 756(\mathrm{~s}), 706(\mathrm{w}), 679(\mathrm{~s})$.

Synthesis of $\left[\mathrm{Dy}\left(\mathrm{DAD}^{2 \mathrm{Me}}\right)(\mu-\mathrm{Cl})(\mathrm{THF})_{2}\right]_{2}$ (2). The synthetic procedure analogous to that for 1 was used. $\mathrm{K}_{2}[2,6-$ $\left.i \mathrm{Pr}_{2} \mathrm{C}_{6} \mathrm{H}_{3} \mathrm{NC}(\mathrm{Me}) \mathrm{C}(\mathrm{Me}) \mathrm{NC}_{6} \mathrm{H}_{3} i \mathrm{Pr}_{2}-2,6\right]$ ( $\left.\mathrm{THF}\right)_{\mathrm{n}}$ in situ prepared from 2,6-i $\mathrm{Pr}_{2} \mathrm{C}_{6} \mathrm{H}_{3} \mathrm{NC}(\mathrm{Me}) \mathrm{C}(\mathrm{Me}) \mathrm{NC}_{6} \mathrm{H}_{3} \mathrm{Pr}_{2}-2,6$ (0.80 g, 1.98 $\mathrm{mmol}$ ) and potassium metal $(0.15 \mathrm{~g}, 3.96 \mathrm{mmol}) ; \mathrm{DyCl}_{3}(0.53 \mathrm{~g}$, $1.98 \mathrm{mmol}) .2$ was isolated as orange crystals $(0.90 \mathrm{~g}, 61 \%$ yield). Elemental analysis calcd. (\%) for $\mathrm{C}_{72} \mathrm{H}_{112} \mathrm{Cl}_{2} \mathrm{Dy}_{2} \mathrm{~N}_{4} \mathrm{O}_{4}$ (1494.66 g. $\mathrm{mol}^{-1}$ ): C, 57.90; H, 7.56; Dy, 21.76; N, 3.75; found (\%): C, 58.11; H, 7.81; Dy, 21.98; N, 3.89. IR (Nujol, KBr) v/cm ${ }^{-1}$ : $1875(\mathrm{~m}), 1831(\mathrm{~m}), 1790(\mathrm{~m}), 1736(\mathrm{~m}), 1666(\mathrm{~m}), 1592(\mathrm{~s})$, $1519(\mathrm{~m}), 1377$ (s), 1362 (s), 1342 (s), 1305 (s), 1257 (s), 1201 (s), 1171 (s), 1152 (s), 1132 (s), 1113 (s), 1083 (s), 1019 (s), 954 $(\mathrm{m}), 922(\mathrm{~s}), 909(\mathrm{~s}), 895(\mathrm{~s}), 887(\mathrm{~s}), 866(\mathrm{~s}), 844(\mathrm{~s}), 817(\mathrm{~s})$, $799(\mathrm{~s}), 704(\mathrm{~m}), 685(\mathrm{~m}), 672(\mathrm{~m})$.

Synthesis of $\left[\mathrm{Dy}\left(\mathrm{DAD}^{2 \mathrm{H}}\right) \cdot{ }^{-} \mathrm{Cl}_{2}(\mathrm{THF})_{2}\right]$ (3). A solution of $\mathrm{K}^{+}[2,6-$ $\left.i \mathrm{Pr}_{2} \mathrm{C}_{6} \mathrm{H}_{3} \mathrm{NC}(\mathrm{H}) \mathrm{C}(\mathrm{H}) \mathrm{NC}_{6} \mathrm{H}_{3} i \mathrm{Pr}_{2}-2,6\right]^{-}$(THF $)_{\mathrm{n}}$ in situ obtained from 2,6-i $\mathrm{Pr}_{2} \mathrm{C}_{6} \mathrm{H}_{3} \mathrm{NC}(\mathrm{H}) \mathrm{C}(\mathrm{H}) \mathrm{NC}_{6} \mathrm{H}_{3} i \mathrm{Pr}_{2}-2,6(0.60 \mathrm{~g}, 1.59 \mathrm{mmol})$ and $\mathrm{K}$ shavings $(0.062 \mathrm{~g}, 1.59 \mathrm{mmol})$ in $30 \mathrm{~mL}$ of THF was slowly added to a suspension of $\mathrm{DyCl}_{3}(0.43 \mathrm{~g}, 1.59 \mathrm{mmol})$ in THF (5 $\mathrm{mL}$ ) at room temperature. The reaction mixture was stirred for $12 \mathrm{~h}$ at room temperature. The solvents were removed in vacuum and the solid residue was extracted with toluene (40 $\mathrm{mL}$ ). The toluene extract was filtered, toluene was evaporated in vacuum. Recrystallization of the resulting solid from $\mathrm{THF} /$ hexane mixture at $20^{\circ} \mathrm{C}$ afforded red crystals of $\mathbf{3}(0.71 \mathrm{~g}$, $59 \%$ yield). Elemental analysis calcd. (\%) for $\mathrm{C}_{34} \mathrm{H}_{52} \mathrm{Cl}_{2} \mathrm{DyN}_{2} \mathrm{O}_{2}$ $\left(754.27 \mathrm{~g} \cdot \mathrm{mol}^{-1}\right)$ : C, 54.15; H, 6.95; Dy, 21.55; N, 3.71; found (\%): C, 54.43; H, 7.19; Dy, 21.70; N, 3.58. IR (Nujol, $\mathrm{KBr}$ ) v/ $\mathrm{cm}^{-1}$ : $1945(\mathrm{~m}), 1931(\mathrm{~m}), 1918(\mathrm{~m}), 1870(\mathrm{~m}), 1856(\mathrm{~m}), 1807(\mathrm{~m})$, $1793(\mathrm{~m}), 1626(\mathrm{~s}), 1588(\mathrm{~s}), 1538(\mathrm{~m}), 1364(\mathrm{~s}), 1329(\mathrm{~s}), 1293$ (s), $1254(\mathrm{~s}), 1179(\mathrm{~s}), 1161(\mathrm{~m}), 1104$ (s), 1072 (s), 1059 (s), $1042(\mathrm{~s}), 1017$ (s), $954(\mathrm{~s}), 924(\mathrm{~s}), 869(\mathrm{~s}), 846(\mathrm{~m}), 819(\mathrm{~m})$, $797(\mathrm{~s}), 757(\mathrm{~s}), 694(\mathrm{~m}), 674(\mathrm{~m})$. 
Synthesis of [Dy(DAD $\left.\left.{ }^{2 \mathrm{Me}}\right) \mathrm{Cl}_{2}(\mathrm{THF})_{2}\right]$ (4). An analogous synthetic procedure to that for 3 was used. $\mathrm{K}^{+}[2,6-$ $\left.i \mathrm{Pr}_{2} \mathrm{C}_{6} \mathrm{H}_{3} \mathrm{NC}(\mathrm{Me}) \mathrm{C}(\mathrm{Me}) \mathrm{NC}_{6} \mathrm{H}_{3} i \mathrm{Pr}_{2}-2,6\right]^{-}(\mathrm{THF})_{\mathrm{n}}$ in situ prepared from 2,6-i $\mathrm{Pr}_{2} \mathrm{C}_{6} \mathrm{H}_{3} \mathrm{NC}(\mathrm{Me}) \mathrm{C}(\mathrm{Me}) \mathrm{NC}_{6} \mathrm{H}_{3} \mathrm{Pr}_{2}-2,6 \quad(0.70 \mathrm{~g}, \quad 1.73$ $\mathrm{mmol}$ ) and potassium shavings $(0.067 \mathrm{~g}, 1.73 \mathrm{mmol})$ with $\mathrm{DyCl}_{3}$ (0.46 g, $1.73 \mathrm{mmol})$. Recrystallization of the resulting solid from THF/hexane mixture at $20{ }^{\circ} \mathrm{C}$ afforded red crystals of 4 (0.65 g, 48\% yield). Elemental analysis calcd. (\%) for $\mathrm{C}_{36} \mathrm{H}_{55} \mathrm{Cl}_{2} \mathrm{DyN}_{2} \mathrm{O}_{2}\left(781.29 \mathrm{~g} \cdot \mathrm{mol}^{-1}\right): \mathrm{C}, 55.35 ; \mathrm{H}, 7.10 ; \mathrm{Dy}, 20.80$; $\mathrm{N}, 3.59$; found (\%): C, 55.51; H, 7.28; Dy, 20.95; N, 3.37. IR (Nujol, KBr) v/cm ${ }^{-1}: 1957(\mathrm{~m}), 1923(\mathrm{~m}), 1886(\mathrm{~m}), 1855(\mathrm{~m})$, $1815(\mathrm{~m}), 1796(\mathrm{~m}), 1753(\mathrm{~m}), 1715(\mathrm{~m}), 1697(\mathrm{~m}), 1643(\mathrm{~m})$, 1576 (s), 1545 (s), 1364 (s), 1349 (s), 1317 (s), 1245 (s), 1206 (s), 1182 (s), 1149 (s), 1104 (s), 1056 (s), 1014 (s), 985 (s), 959 $(\mathrm{s}), 938(\mathrm{~s}), 920(\mathrm{~s}), 893(\mathrm{~s}), 865(\mathrm{~s}), 849(\mathrm{~s}), 827(\mathrm{~m}), 806(\mathrm{~s})$, $789(\mathrm{~s}), 744(\mathrm{~s}), 709(\mathrm{~s}), 697(\mathrm{~m}), 667(\mathrm{~s})$.

\section{X-ray crystallography}

The X-ray data for 1-4 were collected on Bruker D8 Quest (1, $T$ = 100(2) K), Bruker Smart Apex II (2-3, T=120(2) K) and Rigaku $O D$ Xcalibur $(4, T=120(2) \mathrm{K})$ diffractometers $\left(M o_{K \alpha}\right.$-radiation, $\omega$-scans technique, $\lambda=0.71073 \AA \AA$ ) using $A P E X 3^{73}$ and CrysAlis ${ }^{\text {Pro } 74}$ software packages. The structures were solved by direct methods and were refined by full-matrix least squares on $F^{2}$ for all data using SHELX. ${ }^{75}$ SADABS ${ }^{76}$ and CrysAlis ${ }^{\text {Pro }}$ were used to perform area-detector scaling and absorption corrections. Structure of $\mathbf{4}$ was refined as two-component

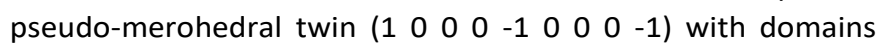
ratio $0.43 / 0.57$. All non-hydrogen atoms were found from Fourier syntheses of electron density and were refined anisotropically. Atoms $\mathrm{H}(1), \mathrm{H}(2)$ in $\mathbf{1}, 3$ and $\mathrm{H}$ atoms at $\mathrm{C}(2)$, $\mathrm{C}(4)$ carbon atoms in $\mathbf{4}$ also were found from Fourier syntheses of electron density and were refined isotropically (hydrogen atoms in $\mathbf{4}$ were refined using $A F I X$ instructions). Other hydrogen atoms in 1-4 were placed in calculated positions and were refined in the "riding" model with $U(H)_{i s o}=1.2 U_{\text {eq }}$ of their parent atoms $\left(U(H)_{i s o}=1.5 U_{\text {eq }}\right.$ for methyl groups).

The crystallographic data and structure refinement details for 1-4 are given in Table S1 (see ESI). CCDC-2004738 (1), 2004739 (2), 2004740 (3) and 2004741 (4) contains the supplementary crystallographic data for this paper. These data are provided free of charge by The Cambridge Crystallographic Data Centre: ccdc.cam.ac.uk/structures.

\section{Magnetic measurements}

Magnetic susceptibility data were collected with a Quantum Design MPMS-XL SQUID magnetometer working in the range $1.8-350 \mathrm{~K}$ with the magnetic field up to 7 Tesla. The samples were prepared in a glove box. The data were corrected for the sample holder and the diamagnetic contributions calculated from the Pascal's constants. The ac magnetic susceptibility measurements were carried out in the presence of a 3 Oe oscillating field in zero or applied external dc field.

\section{Conflicts of interest}

There are no conflicts to declare.

\section{Acknowledgements}

The Russian co-authors thank the Russian Science Foundation (grant 17-73-30036). X-ray study of complexes 1 and 4 has been carried out in the framework of the Russian state assignment using the equipment of The Analytical Center of IOMC RAS. The X-ray study has been carried out using an equipment of The Analytical Centers of IOMC RAS and INEOS RAS. The authors thank the University of Montpellier and CNRS for financial supports and Platform of Analysis and Characterisation of ICGM for magnetic measurements.

\section{Notes and references}

¥ Footnotes relating to the main text should appear here. These might include comments relevant to but not central to the matter under discussion, limited experimental and spectral data, and crystallographic data.

1 D. N. Woodruff, R. E. P. Winpenny and R. A. Layfield, Chem. Rev., 2013, 113, 5110-5148.

2 S. T. Liddle and J. van Slageren, Chem. Soc. Rev., 2015, 44, 66556669.

3 Z.-P. Ni, J.-L. Liu, M. N. Hoque, W. Liu, J.-Y. Li, Y.-C. Chen and M.L. Tong, Coord. Chem. Rev., 2017, 335, 28-43.

4 Z. Zhu, M. Guo, X.-L. Li and J. Tang, Coord. Chem. Rev., 2019, 378, 350-364.

5 J. Luzon and R. Sessoli, Dalton Trans., 2012, 41, 13556-13567.

6 F. Troiani and M. Affronte, Chem. Soc. Rev., 2011, 40, 31193129.

7 L. Bogani and W. Wernsdorfer, Nat. Mater., 2008, 7, 179-186.

8 M. J. Giansiracusa, A. K. Kostopoulos, D. Collison, R. E. P. Winpenny and N. F. Chilton, Chem. Commun., 2019, 55, 70257028.

9 A. Chiesa, F. Cugini, R. Hussain, E. Macaluso, G. Allodi, E. Garlatti, M. Giansiracusa, C. A. P. Goodwin, F. Ortu, D. Reta, J. M. Skelton, T. Guidi, P. Santini, M. Solzi, R. De Renzi, D. P. Mills, N. F. Chilton and S. Carretta, Phys. Rev. B, 2020, 101, 174402.

10 J. D. Rinehart and J. R. Long, Chem. Sci., 2011, 2, 2078-2085.

11 L. Ungur and L. F. Chibotaru, Inorg. Chem., 2016, 55, 1004310056.

12 C. A. P. Goodwin, F. Ortu, D. Reta, N. F. Chilton and D. P. Mills, Nature, 2017, 548, 439-442.

13 L. Escalera-Moreno, J. J. Baldoví, A. Gaita-Ariño and E. Coronado, Chem. Sci., 2018, 9, 3265-3275.

14 A. Lunghi, F. Totti, R. Sessoli and S. Sanvito, Nat. Comm., 2017, 8, 14620.

15 P. Evans, D. Reta, G. F. S. Whitehead, N. F. Chilton and D. P. Mills, J. Am. Chem. Soc., 2019, 141, 19935-19940.

16 J. Liu, Y.-C. Chen, J.-L. Liu, V. Vieru, L. Ungur, J.-H. Jia, L. F. Chibotaru, Y. Lan, W. Wernsdorfer, S. Gao, X.-M. Chen and M.-L. Tong, J. Am. Chem. Soc., 2016, 138, 5441-5450.

17 S. K. Gupta, T. Rajeshkumar, G. Rajaraman and R. Murugavel, Chem. Sci., 2016, 7, 5181-5191.

18 F. S. Guo, B. M. Day, Y. C. Chen, M. L. Tong, A. Mansikkamaki and R. A. Layfield, Angew. Chem. Int. Ed. Engl., 2017, 56, 1144511449.

19 Y.-S. Ding, N. F. Chilton, R. E. P. Winpenny and Y.-Z. Zheng, Angew. Chem. Int. Edit., 2016, 55, 16071-16074.

20 Y.-S. Meng, L. Xu, J. Xiong, Q. Yuan, T. Liu, B.-W. Wang and S. Gao, Angew. Chem. Int. Edit., 2018, 57, 4673-4676.

21 A. B. Canaj, S. Dey, E. R. Martí, C. Wilson, G. Rajaraman and M. Murrie, Angew. Chem. Int. Edit., 2019, 58, 14146-14151. 
22 F.-S. Guo, B. M. Day, Y.-C. Chen, M.-L. Tong, A. Mansikkamäki and R. A. Layfield, Science, 2018, 362, 1400-1403.

23 F.-S. Guo, A. K. Bar and R. A. Layfield, Chem. Rev., 2019, 119, 8479-8505.

24 Y. S. Ding, N. F. Chilton, R. E. Winpenny and Y. Z. Zheng, Angew. Chem., Int. Ed. Engl., 2016, 55, 16071-16074.

25 Y.-C. Chen, J.-L. Liu, L. Ungur, J. Liu, Q.-W. Li, L.-F. Wang, Z.-P. Ni, L. F. Chibotaru, X.-M. Chen and M.-L. Tong, J. Am. Chem. Soc., 2016, 138, 2829-2837.

26 J. Long, I. V. Basalov, N. V. Forosenko, K. A. Lyssenko, E. Mamontova, A. V. Cherkasov, M. Damjanović, L. F. Chibotaru, Y. Guari, J. Larionova and A. A. Trifonov, Chem. Eur. J., 2019, 25, 474-478.

27 Y. S. Ding, T. Han, Y. Q. Zhai, D. Reta, N. F. Chilton, R. E. P. Winpenny and Y. Z. Zheng, Chem. Eur. J., 2020, 26, 5893-5902.

28 Z.-H. Li, Y.-Q. Zhai, W.-P. Chen, Y.-S. Ding and Y.-Z. Zheng, Chem. Eur. J., 2019, 25, 16219-16224.

29 K.-X. Yu, J. G. Kragskow, Y.-S. Ding, Y.-Q. Zhai, D. Reta, N. F. Chilton and Y.-Z. Zheng, Chem, 2020, DOI: 10.1016/j.chempr.2020.04.024.

30 M. J. Giansiracusa, E. Moreno-Pineda, R. Hussain, R. Marx, M. Martínez Prada, P. Neugebauer, S. Al-Badran, D. Collison, F. Tuna, J. van Slageren, S. Carretta, T. Guidi, E. J. L. McInnes, R. E. P. Winpenny and N. F. Chilton, J. Am. Chem. Soc., 2018, 140, 2504-2513.

31 S. Demir, I.-R. Jeon, J. R. Long and T. D. Harris, Coord. Chem. Rev., 2015, 289-290, 149-176.

32 F. Habib and M. Murugesu, Chem. Soc. Rev., 2013, 42, 3278 3288.

33 R. J. Blagg, L. Ungur, F. Tuna, J. Speak, P. Comar, D. Collison, W. Wernsdorfer, E. J. L. Mclnnes, L. F. Chibotaru and R. E. P. Winpenny, Nat. Chem., 2013, 5, 673-678.

34 J. Long, F. Habib, P.-H. Lin, I. Korobkov, G. Enright, L. Ungur, W. Wernsdorfer, L. F. Chibotaru and M. Murugesu, J. Am. Chem. Soc., 2011, 133, 5319-5328.

35 K. Katoh, R. Asano, A. Miura, Y. Horii, T. Morita, B. K. Breedlove and M. Yamashita, Dalton Trans., 2014, 43, 7716-7725.

36 E. M. Pineda, Y. Lan, O. Fuhr, W. Wernsdorfer and M. Ruben, Chem. Sci., 2017, 8, 1178-1185.

37 J. Xiong, H.-Y. Ding, Y.-S. Meng, C. Gao, X.-J. Zhang, Z.-S. Meng, Y.-Q. Zhang, W. Shi, B.-W. Wang and S. Gao, Chem. Sci., 2017, 8, 1288-1294.

38 T. Han, M. J. Giansiracusa, Z.-H. Li, Y.-S. Ding, N. F. Chilton, R. E. P. Winpenny and Y.-Z. Zheng, Chem. Eur. J., 2020, 26, 67736777.

39 Y.-S. Meng, J. Xiong, M.-W. Yang, Y.-S. Qiao, Z.-Q. Zhong, H.-L. Sun, J.-B. Han, T. Liu, B.-W. Wang and S. Gao, Angew. Chem. Int. Edit., 2020, n/a.

40 J. D. Rinehart, M. Fang, W. J. Evans and J. R. Long, Nat. Chem., 2011, 3, 538-542.

41 L. Bogani, C. Sangregorio, R. Sessoli and D. Gatteschi, Angew. Chem. Int. Edit., 2005, 44, 5817-5821.

42 K. Bernot, L. Bogani, A. Caneschi, D. Gatteschi and R. Sessoli, J. Am. Chem. Soc., 2006, 128, 7947-7956.

43 A. Caneschi, A. Dei, D. Gatteschi, S. Poussereau and L. Sorace, Dalton Trans., 2004, DOI: 10.1039/B401144A, 1048-1055.

44 L. Norel, L.-M. Chamoreau, Y. Journaux, O. Oms, G. Chastanet and C. Train, Chem. Commun., 2009, DOI: 10.1039/B816910A, 2381-2383.

45 I. S. Morgan, A. Mansikkamaki, M. Rouzieres, R. Clerac and H. M. Tuononen, Dalton Trans., 2017, 46, 12790-12793.

46 S. Demir, J. M. Zadrozny, M. Nippe and J. R. Long, J. Am. Chem. Soc., 2012, 134, 18546-18549.
47 S. Demir, M. Nippe, M. I. Gonzalez and J. R. Long, Chem. Sci. 2014, 5, 4701-4711.

48 N. Ishikawa, M. Sugita, N. Tanaka, T. Ishikawa, S.-y. Koshihara and Y. Kaizu, Inorg. Chem., 2004, 43, 5498-5500.

49 F.-S. Guo and R. A. Layfield, Chem. Commun., 2017, 53, 3130 3133.

50 J. Long, G. G. Skvortsov, A. Cherkasov, K. A. Lyssenko, A. I. Poddel'sky, Y. Guari, J. Larionova and A. Trifonov, Dalton Trans., 2019, 48, 12018-12022.

51 A. A. Trifonov, B. Shestakov, J. Long, K. Lyssenko, Y. Guari and J. Larionova, Inorg. Chem., 2015, 54, 7667-7669.

52 J. Long, B. G. Shestakov, D. Liu, L. Chibotaru, Y. Guari, A. Cherkasov, G. K. Fukin, A. Trifonov and J. Larionova, Chem. Commun., 2017, 53, 4706-4709.

53 J. Long, A. O. Tolpygin, A. V. Cherkasov, K. A. Lyssenko, Y. Guari, J. Larionova and A. A. Trifonov, Organometallics, 2019, 38, 748752.

54 J. Long, A. Tolpygin, A. Cherkasov, K. A. Lyssenko, Y. Guari, J. Larionova and A. Trifonov, Cryst. Eng. Comm., 2020, 22, 4260 4267.

55 A. A. Kissel, D. M. Lyubov, T. V. Mahrova, G. K. Fukin, A. V. Cherkasov, T. A. Glukhova, D. Cui and A. A. Trifonov, Dalton Trans., 2013, 42, 9211-9225.

56 A. A. Kissel, T. V. Mahrova, D. M. Lyubov, A. V. Cherkasov, G. K. Fukin, A. A. Trifonov, I. Del Rosal and L. Maron, Dalton Trans., 2015, 44, 12137-12148

57 A. A. Kissel, T. V. Mahrova, D. M. Lyubov, A. V. Cherkasov, G. K. Fukin, A. A. Trifonov, I. Del Rosal and L. Maron, Dalton Trans., 2015, 44, 12137-12148

58 D. Casanova, M. Llunell, P. Alemany and S. Alvarez, Chem. Eur. J., 2005, 11, 1479-1494.

59 T. V. Laine, M. Klinga, A. Maaninen, E. Aitola and M. Leskela, Acta Chem. Scand., 1999, 53, 968-973.

60 S.-S. Liu, Y.-S. Meng, Y.-Q. Zhang, Z.-S. Meng, K. Lang, Z.-L. Zhu, C.-F. Shang, B.-W. Wang and S. Gao, Inorg. Chem., 2017, 56, 7320-7323.

61 S. V. Klementyeva, M. Y. Afonin, A. S. Bogomyakov, M. T. Gamer, P. W. Roesky and S. N. Konchenko, Eur. J. Inorg. Chem., 2016, 2016, 3666-3672.

62 F. H. Allen, O. Kennard, D. G. Watson, L. Brammer, A. G. Orpen and R. Taylor, J. Chem. Soc.,Perkin Trans. 2, 1987, DOI: 10.1039/P298700000S1, S1-S19.

63 A. A. Trifonov, E. A. Fedorova, I. A. Borovkov, G. K. Fukin, E. V. Baranov, J. Larionova and N. O. Druzhkov, Organometallics, 2007, 26, 2488-2491.

64 I. L. Fedushkin, D. S. Yambulatov, A. A. Skatova, E. V. Baranov, S. Demeshko, A. S. Bogomyakov, V. I. Ovcharenko and E. M. Zueva, Inorg. Chem., 2017, 56, 9825-9833.

65 A. A. Trifonov, I. D. Gudilenkov, J. Larionova, C. Luna, G. K. Fukin A. V. Cherkasov, A. I. Poddel'sky and N. O. Druzhkov, Organometallics, 2009, 28, 6707-6713.

66 Y.-N. Guo, G.-F. Xu, Y. Guo and J. Tang, Dalton Trans., 2011, 40, 9953-9963.

67 K. R. Meihaus, S. G. Minasian, W. W. Lukens, S. A. Kozimor, D. K. Shuh, T. Tyliszczak and J. R. Long, J. Am. Chem. Soc., 2014, 136, 6056-6068.

68 K. N. Shrivastava, physica status solidi (b), 1983, 117, 437-458.

69 N. F. Chilton, D. Collison, E. J. L. Mclnnes, R. E. P. Winpenny and A. Soncini, Nat. Commun., 2013, 4, 2551.

70 M. D. Taylor and C. P. Carter, J. Inorg. Nucl. Chem., 1962, 24, 387-391.

71 M. Svoboda and H. t. Dieck, J. Organomet. Chem., 1980, 191, 321-328.

72 S. J. Lyle and M. M. Rahman, Talanta, 1963, 10, 1177-1182. 
73 Bruker, APEX 3 and SAINT, 2018, B. A. Inc., Madison, Winsconsin, USA.

74 R. Corporation, CrysAlisPro, 2018, R. Corporation, Wroclaw, Poland.

75 G. M. Sheldrick, Acta Crystallogr., Sect. C: Struct. Chem., 2015, 71, 3-8.

76 L. Krause, R. Herbst-Irmer, G. M. Sheldrick and D. Stalke, J. Appl. Crystallogr., 2015, 48, 3-10. 